\title{
EL REFORMISMO DE GONZÁLEZ DE CELLORIGO Y SUS FUENTES: MAQUIAVELO Y BODIN
}

por

\section{JESUS VILLANUEVA}

Universidad Autónoma de Barcelona

RESUMEN: Se muestra cómo el "Memorial de la politica restauración de España" (1600) del arbitrista $M$. González de Cellorigo está ampliamente basado en la "República" de J. Bodin e incluye una adaptación más breve de un capítulo de los "Discursos sobre T. Livio" de N. Maquiavelo, el que trata del "retorno a los principios" (III I). A partir de estos dos autores analiza Cellorigo la dinámica de decadencia del Estado, para proponer como solución el restablecimiento de la autoridad pública mediante las actuaciones intimidatorias recomendadas por Maquiavelo, y una reforma socioeconómica centrada en la clase media que debia ejecutarse según las normas de Bodin. Se considera el Memorial de Cellorigo como un ejemplo de fusión de la doctrina de la razón de Estado con la concepción política medieval. Se incluyen dos apéndices con la transcripción de los pasajes que Cellorigo toma literalmente de Maquiavelo y Bodin.

Palabras clave. España, S. 17, Pensamiento político, González de Cellorigo, Machiavelli, Bodin.

ABSTRACT: It is shown that "Memorial de la politica restauración de España» (1600) by the Spanish "arbitrista» $M$. Gonzallez de Cellorigo is largely based on Bodin's "Republic" and also includes a briefer adaptation of a chapter of Machiavelli's "Discourses on $T$. Livy", that concerned with the "return to the beginnings" (III 1). Resting on these two authors, Cellorigo discusses the process of decline of the state, proposing as remedy the restauration of public authority by way of the intimidatory exploits lauded by Machiavelli, as well as a socio-economic reform focused on the middle class which should be executed following Bodin's rules. Cellorigo's "Memorialn is finally considered as a characteristic example of the mixing of the modern doctrine of reason of state and the medieval political conception. Two final apendices display the passages wich Cellorigo borrows directly from his sources.

ARSTRACT: KeY worDs: Spain, xvir century, González de Cellorigo. 
Martín González de Cellorigo es tal vez el más destacado de los «arbitristas» castellanos del siglo xvil. Su Memorial de la politica restauración de España, publicado en el año 1600, ' ya en la época tuvo una notable repercusión, aunque su autor no recibiera el esperado reconocimiento, y orientó el curso del pensamiento económico español de todo el siglo ${ }^{2}$. Posteriormente ha sido privilegiado por la historiografía como testimonio de la crisis castellana de esos años ${ }^{3} \mathrm{y}$ ha sido varias veces estudiado dentro de la historia de la literatura económica ${ }^{4}$. Más allá de esto, aunque generalmente se ha apre-

1 Memorial de la política, necesaria y útil restauración a la república de España y estados de ella, $y$ del desempeño universal de estos reinos, Valladolid, 1600, 66 ff. Existe una edición reciente al cuidado de PÉrez DE AvaLA, J. L., en los Clásicos del Pensamiento Económico Español del Instituto de Estudios Fiscales (Madrid, 1991, 193 p.), que es la que cito; sin embargo, la transcripción es un tanto descuidada y se omiten las notas marginales, por lo que debe completarse con la edición original. - Cellorigo se refiere a este Memorial como su Politica restauración (cf. nota sig.); tal vez habtia entonces que titularlo como sugiero arriba (y no Memorial de la política necesaria etc.).

2 El Memorial fute un encargo de Felipe 1], que quedó muy complacido con los Memoriales sobre el problema de los moriscos (impreso uno al final de la edición original del Memorial que nos ocupa) que Cellorigo le presentó en 1597, como éste explica en una posterior Alegución en favor de un grupo de judeoconversos (editada por RÉVAH, 1. S., en Revue des études juives, 122, 1963): «Pues aviendo el rey don Felipe II... visto los memoriales impressos que le di sobre la forma de la expulsión de los moriscos, por contentarle tanto me mandó que escriviesse sobre la razón de estado perteneciente a la restauración destos Reynos, y al punto me bolvi a Valladolid y escriví la Politica restauración dellos» $(\S 78)$, aunque en este último Memorial dice que fue a Felipe IIJ cuando aún era príncipe a quien entregó aquellos Memoriales (cf. 5, 133). Se queja en la mencionada Alegación (\$ 6 y 1 14) del ningún provecho que habria sacado de su escrito, cuya impresión él mismo había costeado ("cyo lo trabajé y imprimi a mis proprias expensas»): tan sólo algún desaprensivo lo habria utilizado en interés propio, sin reconocer la procedencia («bien sé que se han sacado algunos apuntamientos de aquella Politica, sin alegar el autor, haziéndose dueños dellos los que los han propuesto, y yo solo y arrinconado, mirando a otros luzir con ellos"; tal vez se refiriera al memorial publicado en el Archivo Histórico Español, V, doc. 42; tambièn lo plagió Rojas Villandrando, según señalaba CostA, Joaquín, Colectivismo agrario, pt. 1, c. $3, \S 6$ ), mientras que en el extranjero se apreciaba hasta el punto de ser traducido ( $«$ lo que por mí anda escrito en lo que toca a la restauración destos reinos..., aprovechándose de ello los estranjeros, lo han cogido y traducido para su aprovechamiento; porque... por ser muy ordinario que ninguno es acetado en su patria tanto como en la agena, lo que los nuestros tienen cabe sí, los estrangeros honran y autorizany). En cuanto a su influencia práctica, debe notarse que el Memorial figuraba en la biblioteca del conde-duque de Olivares (ELLIOTT, J. H., El conde-duque de Olivares, Barcelona 1990, 137), y ciertamente tiene muchos puntos en común con el programa político olivarista.

3 VILAR, P., «El tiempo del Quijote», en Crecimiento y desarrollo, Barcelona 1980, cf. 340 s.; ELLIOTT, op, cit, $108 \mathrm{~s}$. (y su ensayo (Introspección cotectiva y decadencia en España", en Poder y sociedad en la España de los Austrias, Barcelona 1982). También ViLAR, J., Literatura y economia, La figura del arbitrista en la literatura del siglo de oro, Madrid 1973, cf. 185 s., 229.

4 Colmeiro, M., Biblioteca de los economistas españoles, § 2!8; Costa, J., loc, cit,; el amplio resumen de Carrera Pujal, J., Historia de la economía española, 1, 358-378; Sureda, J. L., La hacienda castellana y los economistas del siglo XVIJ, Madrid 1949, passim; el estudio de PÉREZ DE Ayala, J. L., en Revista de Derecho Financiero y de Hacienda Pública, 9 (1959), así como la introd. a su reciente edición del Memorial; LARRAZ, J., La época del mercantilismo en Castilla, Madrid 1963, 88-90; CAlLE, R., La hacienda pública en España, Un análisis de la literatura financiera, Mad̛rid 1978, c. 1; Lórez-VIviĖ, 1., en Diez econonistas españoles, siglos XVI-XVII, ed. J. de la lglesia, El Escorial 1991, 281 ss.

Hisponia, LVII/1, nủm. 195 (1997) 63-92 
ciado la elevación del pensamiento del autor ${ }^{5}$, no se ha intentado un análisis doctrinal del Memorial situándolo dentro del contexto intelectual de la época. Es cierto que la teoría moral que en él se desarrolla ha sido analizada recientemen te en este sentido, localizándola en la decisiva coyuntura de la década en torno a $1600^{6}$. Pero falta un tratamiento monográfico de la parte tal vez más importante de la obra, la doctrina política, pues su autor se consideraba a sí mismo ante todo como "político" y era en este aspecto en el que hacía residir su aportación más novedosa.

A este fin una lectura atenta descubre dos evidencias que hasta ahora no han sido debidamente señaladas. En primer lugar, que el Memorial de Cellorigo es en su conjunto una amplia y directa adaptación de la República de Jean Bodin ${ }^{7}$. En segundo lugar, que contiene una adaptación más localizada de un capítulo de los Discursos sobre Tito Livio de Nicolás Maquiavelo. Naturalmente, éstas no son influencias casuales ni deben interpretarse únicamente en términos de originalidad literaria. La adaptación que de ambos autores hace Cellorigo debe verse ante todo como una consciente adhesión a las corrientes ideológicas del maquiavelismo y sobre todo del bodinismo que en esos años agitaban la vida intelectual europea. La intencionalidad se pone aún más de manifiesto por la precaución que Cellorigo toma de no citar expresamente sus fuentes: protegiendo de este modo el contenido doctrinal de las sospechas que suscitaban los nombres de los dos autores, Cellorigo esperaría realizar su plan de introducir en España la ciencia política moderna, con la convicción de que ésta ofrecía la base de la política que la monarquía espanola debía seguir para enfrentarse a la crisis que la cercaba ${ }^{8}$. Respecto a los

$s$ «la doctrina de sus memoriales excede en mucho a la común opinión... casi siempre se muestra superior a sus contemporáneos» (Colmeiro); «voz grave y filosófica... sano espiritu conservador" (Larraz); "obra... excepcionalmente elevada en su análisis» (J. Vilar). Para P. Vilar, Cellorigo es un «arbitrista-teólogo» y quien inaugura propiamente el debate sobre la decadencia castellana.

- Cavillac, M., Picaros y mercaderes en el Guzmán de Alfarache, Granada 1994 (ed. fr. 1983), cap. 5 passim (señala la proximidad ideológica entre Mateo Alemán y Cellorigo).

$\gamma$ Alburquerque, M. de, cita en su monografia únicamente las referencias expresas de Cellorigo a Bodin, que precisamente no son préstamos literales (Jean Bodin na península ibérica, París $1978,163-165$ ). Por su parte Jean Vilar ha advertido el plagio de Bodin que Cellorigo comete en determinado pasaje, pero no sé si ha llegado a comprobar la generalidad del procedimiento (en una comunicación privada que reproduce Pérez de Ayala al final de la Introd. de su ed.).

8 Suele introducir los trozos de cualquiera de los dos autores, mediante la fórmula: «los que de esta materia escriben...» $(95,141)$ o «como a este propósito dicen los repúblicos» o «algunos de los que mejor han escripto en materia de estado» (102), pero no puede evitar deslizar el debido elogio: así dice «como dice un gran repúblico» refiriéndose a Bodin $(163,191)$, y revela su conocimiento del autor maldito cuando tras citar a Títo Livio dice: «de quien como del que más descubrió la razón de estado muchos repúblicos siguen sus décadas por leyes y ordenanzas de buen gobierno...) (108). A Bodin lo menciona expresamente en cuatro ocasiones (cf. notas 18,54,55,63), pero siempre de forma genérica, sin precisar la fuente en el margen, como hace con los demás autores. - Naturalmente, no son éstas sus únicas fuentes. Cita expresamente a Pierre Grégoire en varias ocasiones, así como a Francesco Patrizi y Giovanni Botero. Entre las fuentes más propiamente jurídicas tal vez pueden destacarse las obras de Tiraqueaux, Chasseneaux y Alciato, y las fuentes primarias habituales, especialmente las Partidas con los comentarios de Gregorio López.

Hispania, LVII/1, núm. 195 (1997) 63-92 
resultados de esta operación, es destacable tanto la amplitud de la adaptación, especialmente de Bodin, como la forma en que Cellorigo simplifica las teorías originales y las ajusta a su propia temática y mentalidad, aunque en términos más generales es también digna de atención la fusión que realiza entre maquiavelismo y bodinismo, y la conexión que al mismo tiempo establece entre esta doctrina de la razón de Estado y algunos motivos más tradicionales. En todo ello se pone de manifiesto una profunda conciencia política, resultado a su vez de una experiencia personal e histórica peculiar 9 .

Todo ello hay que rastrearlo en una obra con una composición especial. El Memorial empieza planteando la problemática, que desde entonces se haría común, de la decadencia castellana, centrándola en la cuestión demográfica y la del «espíritu capitalistan. Comprende, pues, un análisis económico y sociológico al que siguen una serie de propuestas prácticas de reforma que culminan en un típico "arbitrion fiscal, que representa el objetivo inmediato del Memorial. Pero la obra no se reduce a estas propuestas, y por ello no debe considerarse como una pieza exclusiva mente «arbitristan, sino que junto a ellas se desliza una doctrina política más profunda, tomada toda ella de un autor, Bodin. Esta dualidad de intención se refleja en la estructura de la obra, que parece un tanto desordenada y precipitada. Las tres partes en que se divide sólo ligeramente responden a una distribución efectiva de contenidos. Anticipa que la primera parte tratara de la decadencia de los Estados y en particular de la de España, la segunda sobre los medios para superar dicha decadencia, y la tercera particularmente sobre el programa de saneamiento de la

9 Dentro del maquiavelismo español (véase el balance de MARAVALL, J. A., en sus Estudios de historia del pensamiento español, IIl, o en el Boletín de la R. Academia de la Historia, 165, 1969; últimamente Puigdoménech, Helena, Maquiavelo en España, Presencia de sus obras en los siglos xVI $y$ xVIL, Madrid 1988, limitado a la censura, las traducciones y la presencia en las bibliotecas), Cellorigo destaca por utilizar, aunque sea muy restringidamente, los Discursos sobre T. Livio, una obra que por su republicanismo no podía tener gran predicarnento en la España de la época (aunque no fue totalmente desconocida, cf. FERNÁNDEZ DE LA MORA, G., «Maquiavelo visto por los tratadistas españoles de la Contrarreforma», Arbor, 13, 1949, nota 30). Dentro del bodinismo destaca por la amplitud de su lectura de la República (cita pasajes de cada uno de sus seis libros) y por su adopción de la idea reformista bodiniana, mientras que los demás autores bodinianos españoles tendieron a centrarse específicarnente en la idea de soberanía. Sobre el bodinismo español véanse los datos sobre la recepción que reúnen BENEYTo, J., «Recepción y réplica del pensamiento político moderno en la España del Siglo de Oron, Revista de historia del derecho (Granada), 2 (1978-79), esp. 100 104 (a propósito de Cellorigo señala únicamente la recepción de la idea de soberania); GUTtÉrRez, A., La France et les Français dans la littérature espagnole, 1598-1665, Saint-Etienne 1977, 241246; y Bermejo, J. L., en la Introd. a su ed. de la trad. de G. de Añastro de la República de Bodin, Madrid 1992, 117-129; así como la interpretación tradicional de MARAVALL, Teoría española del Estado en el siglos XVII, Madrid 1944, 94-99, 190 ss., articulada únicamente en torno al concepto de soberanía, y la monografía ya citada de Alburquerque, centrada en la misma cuestión. En relación con sus pretensiones, Cellorigo podría compararse con Baltasar Álamos de Barrientos. Ambos se consideran a sí mismos como pioneros de la ciencia política en España y buscan introducir métodos de gobierno más «racionales». Para uno la solución será el bodinismo, mientras que el otro elegirá el tacitismo de Lipsio.

Hispenia, LVIL/1, núm. 195 (1997) 63-92 
hacienda real (el "desempeño") y la reforma social (la «restauración") que debía acompañarlo. Pero no sólo esos temas aparecen tratados en cualquiera de las tres partes, sino que a lo largo de la obra se encuentran secciones sobre cuestiones políticas particulares o generales que visiblemente no responden a la intención inmediata de la obra. Parecen más bien el resultado de los estudios políticos previos del autor (o más bien del estudio de la República de Bodin), piezas sueltas reunidas aprovechando la ocasión del Memorial, y que tal vez serían borradores del tratado general de política en que iba trabajando y que no publico, según propia confesión, a causa del poco provecho que sacó de su Memorial ${ }^{10}$.

\section{EL. BODINISMO DE CELLORIgo}

La inspiración bodiniana en el Memorial es dominante de principio a fin. Así, la dedicatoria a Felipe III es un remedo del Prefacio de la República de Bodin, con la imagen del Estado como una nave envuelta por una borrasca, a cuya salvación concurren los pasajeros además del patrón y piloto $\left(5 \mathrm{~s}\right.$.) ${ }^{11}$; mientras que el último apartado del Memorial es una adaptación del último capítulo de la República bodiniana, con su teoría del gobierno armónico. Entremedio recoge Cellorigo un gran número de temas bodinianos, hasta el punto que se trasluce la pretensión de asumir la totalidad del pensamiento del autor francés. Su procedimiento será transcribir largos pasajes en secciones independientes o como trasfondo teórico de sus propuestas, o bien acomodándolos más intencionadamente a sus propias ideas ${ }^{12}$.

10 En la Dedicatoria explica cómo, «habiéndome inclinado al estudio de la política en las horas que podía quitar a otras ocupaciones, vine a descubtir grandes y eminentes daños en nuestra repúblican, siendo el principal de ellos el declive demográfico. Emprendería entonces un análisis general de la situación española, hasta que, "después de haber escrito gran parte de lo comenzado», la última epidemia de peste le hizo cambiar el plan: «salí del camino ordinario y general en que iba y tomé el particular de sólo proponer lo que parece convenir a su remedion, convirtiendo la cuestión del «desempeño» en el centro del escrito. Convirtió de este modo un estudio general en un memorial arbitrista. A su tratado de política se refiere en la Alegación sobre los judeoconversos ( $\$ 78)$, tras comentar la usurpación que se cometió sobre su Memorial tras su publicación: «Esto es lo que me ha hecho retener los libros de República que he escrito...» Tras su Memorial sólo publicó en 1619 la citada Alegación, en la que vuelve a incluir extensos apartados de teoría política, entre los que figuran las consiguientes adaptaciones de la doctrina bodiniana. ElLiotT cita además una carta al presidente del Consejo de Castilla de 5 feb. 1619 («Introspección colectiva», nota 44).

II En adelante los números de página entre paréntesis en el texto remiten al Apéndice II, donde se transcriben los pasajes de Bodin tomados literalmente por Cellorigo.

12 La adaptación la hace a partir de la traducción española de Gaspar de Afnastro Isunza, publicada en Turin en 1590 (nueva ed. por J. L. Bermejo, 1992). Sin seguirla literalmente, Cellorigo adopta gran parte de la terminologia de Añastro (p. ej. traduce estat florissant por «estado florido", o souveraineté por "autoridad suprema"), reproduce algún añadido del traductor (cf. infr. nota 18 ), y en general se beneficia de la notable fidelidad de una traducción que se anunciaba, sin embargo, como «católicamente enmendada».

Hispania, LVIL/1, núm. 195 (1997) 63-92 
Respecto a la teoría política general de Bodin, parece asumir Cellorigo la nueva idea de soberanía contenida en la definición bodiniana del Estado como «un justo gobierno de muchas familias y de lo común a ellas con suprema autoridad 13 , en la distinción de una «autoridad suprema» dependiente del príncipe dentro de la jerarquía de los magistrados ${ }^{14}$, en la definición de la ley como un mandato (101), o en la idea del príncipe como enviado o imagen de Dios y como dotado de inviolabilidad, con la consiguiente advertencia contra el tiranicidio (120 s.). Pero el énfasis del original aparece diluido. Así, la «autoridad supreman se reivindica en favor no del rey, sino de un tribunal supremo frente a los inferiores; la fórmula terminante de Bodin de que, siendo el príncipe imagen de Dios, la ley que promulga se ajusta al modelo de la ley de Dios, aparece en Cellorigo un tanto atenuada (105) ${ }^{15}$; y la definición de Estado aparece significativa mente yuxtapuesta a la idea de la armonía del Estado ${ }^{16}$. No es Cellorigo, pues, un teórico de la soberanía. La nota peculiar de su pensamiento aparece en su preocupación genérica por la preservación del principio de autoridad: así entre los jueces, que están obligados a someterse a una estricta jerarquía (naturalmente, no considera la cuestión del derecho de resistencia en ese grupo) y cuya tendencia a la lenidad denuncia de acuerdo con el correspondiente pasaje bodiniano (61). Llega incluso a proponer la revitalización del sistema de supervisión de la administración judicial según la análoga propuesta bodiniana del restablecimiento de la censura ${ }^{17}$. Igualmente, su denuncia del desarreglo de la moral familiar culmina en la ponderación bodiniana de la autoridad patriarcal (63 s.), y el problema de la mendicidad debía resolverse con los expeditivos medios que proponía Bodin ${ }^{18}$.

13 Reproduce la definición de Bodin en tres ocasiones $(30,88,123)$, sin emplear el término soberanía, novedad que Añastro no admitió.

14 «el poder absoluto y suprema autoridad que sólo está en el príncipe, se deriva en todos los magistrados, a unos con autoridad suprema, a otros inferior, $\mathrm{y}$ a otros particular, $\mathrm{y}$ así la república se dice un justo gobierno de muchas familias y de lo común a ellas con suprema autoridads (30, cf. todo el apart. y Apénd. II).

${ }_{15}$ Cf. Bodin: «Porque si la justicia es el fin de la ley, la ley operación del príncipe, el príncipe imagen de Dios, por la misma razón es necesario que la ley del príncipe sea hecha a medida de la ley de Diosn (conclusión de Rep. I 8, trad. Añastro). Además, Cellorigo conserva junto a las fórmulas bodinianas la concepción tradicional del rey justiciero: el pueblo debe amar a su rey, «como enviado de Dios a la tierra para por su mano mantener su república en paz, en justicia y en verdad, y dar a cada uno su derecho, sustentando la armoniosa justicia distributiva y conmutativa, que es por do vienen las repúblicas a reconocer el bien que en el rey tienen... Han de entender los súbditos que el rey ha de ser más amado por el bien que en él puso Dios, y por ser enviado y puesto de su mano...) (116).

1688 (cf. nota 25), 123 (la definición bodiniana abre un apartado sobre la concordia en el Estado).

17 La institución de los visitadores anuales, que ha caido en desuso, ha de producir «el fruto más đichoso, más útil, más necesario» al Estado (180); para Bodin la censura era uune chose si belle, si utile et si necessaires (Rep. VI 1, al principio).

18 Razona la conveniencia de instituir centros de reclusión y trabajo forzoso, y comenta: «De este parecer son los que de la materia de estado han escrito, y lo mismo sigue Juan Bodino, y añade que seria bien que hubiese en cada ciudad casas diputadas para ensentar diversos oficios a los pobres niños, como dice las hay en Paris, en Amberes, en Milán [París, Lyon y Venecia según Bodin] y en otras ciudades de policia, las cuales están adornadas de escuelas públicas de oficiales, que es la mayor

Hisparia. LVIJ/1, núm. 195 (1997) 63-92 
Adopta Cellorigo la tipología bodiniana de los Estados y considera a lo largo de toda la obra a la monarquía española como una «monarquía real y legitima», distinta de la monarquía "señoril" y la tiránica ${ }^{19}$. De ahí sus referencias al "gobierno suave y templado" y según la ley natural del rey de España (129 s.). También considera a la monarquía española como un prototipo del "gobierno armónico» descrito por Bodin, empleando la imagen del Estado como un instrumento musical que gracias al arte del príncipe produce una agradable melodía. Bodin había utilizado esta imagen tradicional como esquema con que organizar un conjunto de "reglas de Estado» de filiación maquiavélica, convirtiendo la «justicia armónican en el objeto de una nueva forma de prudencia política con que se distinguiría su República de la de los autores antiguos. Uno de los medios de acción con que contaba para realizar este tipo de justicia era la "distribución de los premios" por el príncipe. Este debe considerarse ante todo como "autor del premio y la pena», las dos «ataduras" que aseguran la conservación del Estado, como fielmente recoge Cellorigo en el último apartado de su Memorial. Mediante esta distribución de premios el príncipe procederá a una reordenación de las clases, profesiones y caracteres de los súbditos con pretensiones de totalidad, en que no se guiará por el criterio de la justicia moral, sino por el interés del Estado y recurrirá a métodos maquiavélicos. Semejantes cálculos no podían entrar dentro de una mentalidad como la de Cellorigo, que trata de la distribución de premios a propósito del problema de la sobrepoblación de la capital del reino (el príncipe debería despedir de su corte a las personas innecesarias) y que acepta la idea de Bodin de la virtud como fin del Estado sin las sustanciales matizaciones que llevaba consigo (188 s., $189 \mathrm{~s}$.) ${ }^{20}$. Otras "reglas de Estado» que el príncipe bodiniano seguía con vistas a esta meta del gobierno armónico, las

prudencia de que puede usar un reino, porque...» y añade la máxima del Apénd. II (76). - En cambio discrepa del autor francés en la cuestión de los esclavos: aunque su uso «está grandemente por algunos repúblicos impugnado, y sobre todo por el francés Juan Bodino, yo, sintiendo el estado en que están las cosas de España, no tendría por inconveniente la introducción de ellos» (65 s.).

19 «En la justa monarquía de nuestro príncipe, que es de legítimo y natural señor...» (68); «la monarquía real de nuestros reyes... la monarquía senoril, donde los vasallos conquistados, o por mejor decir forzados, reconociendo la vida, los bienes, la libertad de mano del señor, son forciblemente atraídos a una condición servil, indigna de la monarquía real, suave, justa y honesta de nuestros reyes cristianos» (106); «la monarquia real de nuestra España» (161, cf. 180).

20 Para Bodin, p.ej., el príncipe debía seguir el principio maquiavélico (Prínc. c. 8 al fin), «donnant les bien-faicts peu à peu... et les peines tout à coup", con la intermediación de los ministros, que funcionarían como una pantalla (Rep. V 4). Los oficios no deben darse únicamente a los virtuosos, ya que, al igual que en el mundo la armonía resulta de múltiples disonancias, "también la república es compuesta de buenos y malos, de ricos y de pobres, de sabios y de necios, de fuertes y de flacos, unidos por aquellos que son medio entre los unos y los otrosn (VI 6 hacia el fin, trad. Añastro). La imagen naturalista esconde un importante cambio en el fin del Estado, que ya no es la virtud sin más. Sobre el maquiavelismo de Bodin puede verse el pertinente análisis de QUARITSCH, H., en Staatsräson, Studien zur Geschichte eines politischen Begriffs, ed, R. Schnur, Berlín 1975 , 43-63 (cf. 58, donde relaciona la "justicia armónica» con la nueva realidad del Estado soberano, rompiendo con la concepción medieval de la justicia); también Tenenti, A., Stato, Un'ídea, una logica, Bolonia 1987, 243-257.

Hispania, LVII/I, núm. 195 (1997) 63-92 
recoge Cellorigo en los apartados sobre la conveniencia de que el príncipe visite sus dominios $(157)^{21}$, de que se abstenga de ejercer la función de juez (158), o de que se ajuste a las «leyes de la liberalidad» y modere sus excesos (91 s.), todos tomados directamente de Bodin, aunque ignorando la hilazón del original y prescindiendo de las conclusiones de tipo maquiavélico.

En realidad, Cellorigo tiende a reducir el tema de la justicia armónica a una concepción convencional de la "concordia» dentro del Estado ${ }^{22}$, y especialmente al principio de la «correspondencia» entre rey y reino. Ello presupone una reflexión sobre las obligaciones políticas de los ciudadanos, en que sigue basándose en Bodin. De él toma la reafirmación del principio clásico de la desigualdad natural de los hombres $(52,126)$, la fórmula de que los súbditos deben a su príncipe "obediencia, ayuda, socorro y reconocimiento", a cambio de ejusticia, defensa y protección" (138 s., 157), y la definición de súbdito: la "verdadera señal de sujeción" supone, en atención a la precedencia del bien público sobre el particular, el sacrificio por parte del súbdito de sus bienes y aun de su vida (138 s., 155) ${ }^{23}$. Espera que gracias a esta obediencia de los súbditos hacia su príncipe surja un "recíproco amor» y una umuy dulce y alegre armonía» (129 s.). Sin embargo, no duda en reproducir la arremetida de Bodin contra el absolutismo entendido como la pretensión del príncipe de ser dueño absoluto de los bienes de sus súbditos (106 s.), e incluso asume la fórmula bodiniana de la dependencia del príncipe respecto a los «estados del pueblo, comunidades y concejos» $(68,107)$. No por ello habrá Cellorigo de reivindicar el papel de las cortes castellanas, sino que reduce esa dependencia a la cuestión de la población y de la riqueza: el interés del príncipe reside en que el reino esté poblado y sus habitantes se enriquezcan ${ }^{24}$. Es en ese nivel donde se sitúa la correspondencia entre rey y reino, por lo que hay que ver este tema

21 Comenta a este respecto: «es muy necesario que el principe haga sola una ciudad a su reino, y le juzgue y comunique de la misma manera que si fuese una pequeña aldeas (156).

22 Cf. 123 ss., donde parece basarse en P. Grégoire y F. Patrizi.

23. En Bodin esta definición se encuentra en el apartado sobre el «vasallo", que es una figura particular del «ciudadano». Cellorigo lo formula también en el lenguaje de la "correspondencia»: «Es en fin propio interés de los súbditos conservar su rey bueno, sano y libre de todo mal, aunque sea por cuenta de sus vidas y haciendas, que a él han de tener consagradas en todos tiempos y en todas sus necesidades, recibiendo sobre sí todos los golpes de sus trabajos y empeños; dejándose primero hacer pedazos, como hacen las partes del cuerpo en defensa de la cabeza, antes que consentir llegar ningún golpe peligroso al rey, que es su alma, su corazón, su vida, su gobierno y su misma cabeza) (123).

24 Cita el consabido proverbio salomónico «En la multitud del pueblo está la dignidad del príncipe...» (7); al principe, «con la disminución de la gente se le disminuyen las fuerzas, cuyas rentas y grandeza se sustentan en ella» (20); «la mayor riqueza del reino es la mucha gente» (41); «el principe, teniendo gente aplicada al trabajo, tendrá con abundancia todos los frutos que dél proceden, y creciendo sus pueblos en génte, crecerá en tributos, y con ellos y por ellos en grandeza y autoridad» (73); «siendo la mejor y más ilustre renta del rey la mucha y lucida gente de sus estados» (107). Al final de la obra desarrolla el argumento contrario de que conviene evitar las grandes concentraciones de población; aprovecha para ello materiales de Bodin (186), quien sin embargo llegaba a una conclusión opuesta (cf. nota 70).

Hispania, LVIL/, núm. 195 (1997) 63-92 
como un desarrollo independiente por parte de Cellorigo, que conduce a su comprensión de la posibilidad de una reforma ${ }^{25}$.

\section{MAOUIAVELISMO Y RESTABLECIMIENTO DE LA AUTORIDAD DEL ESTADO}

Dados estos presupuestos se esperaría que al tratar de las líneas de una política reformista Cellorigo siguiera también a Bodin. De hecho es así, pero en una sección de la segunda parte del Memorial ${ }^{26}$ se permite introducir un nuevo modelo, el del "retorno a los principios", que encontró en el capítulo inicial del tercer libro de los Discursos sobre la primera década de Tito Livio de Maquiavelo ${ }^{27}$. No duda en combinar las tesis maquiavélicas, que también reproduce literalmente, con conceptos de Bodin, realizando así una curiosa

25 Véanse algunas de sus formulaciones: «teniendo por conclusión asentada, que no sólo importa que los vasallos tengan lo que han menester, sino que lo mismo corra por su rey, porque así como rey y reino son tan correlativos que el bien del rey se comunica al reino y el del reino al rey, de la misma manera en las demás cosas, ora sean buenas, ora sean malas, son tan inseparables que todo les es igual. Lo cual es muy conforme a la definición que se da a la república, a quien dicen que es un justo gobiemo de muchas familias y de lo común a ellas con suprema autoridad donde si el rey es la cabeza y corazón del pueblo, como las leyes lo dicen, es llano que los bienes y los males han de ser cornunes. Por esta causa conviene que pues el ser de ambos consiste en su recíproca conservación, rey y reino se aúnen a la más perpetua y mejor que ser pueda, correspondiéndose con igual socorro de la una parte a la otra» $(87 \mathrm{~s}$.); «no hay cosa más necesaria para la perpetuidad de los estados cuanto que rey y reino se correspondan tan a compás, que a la petición justa del pueblo salga la concorde respuesta del rey, y que a los socorros necesarios que el rey pide acuda la benévola voluntad del reino, y que a los mandatos del príncipe suceda la presta obediencia de los vasallos....) (124) (cf. además 12, $109,118,127,129,161)$. - También Saavedra Fajardo trataba en la Idea de un príncipe político-cristiano, Empresa 60, de la «unión reciproca que hay entre el rey y el reino».

26 Ocupa cuatro apartados, desde el títulado: «Lo mucho que importa para disponer bien el desempeño...» (93-102).

27 Existía una traducción castellana de esta obra por J. L. Ottevanti, publicada en 1552, pero Cellorigo pudo leer el original, ya que también ofrece una traducción de la crónica de Florencia de Mateo Villani. Aparte del citado capitulo no se advierten en el Memorial otros indicios seguros de influencia maquiavélica. Únicamente puede sospecharse que en el siguiente pasaje se esté refiriendo a la teoria de la lucha de clases de Maquiavelo (Disc. I 4): «Y puesto que algunas veces conviene que los vasallos discorden entre si... (no faltando quien diga que con la discordia anda la república más segura que si todos estuviesen confonnes), esto tiene su asiento moral en su lugar, pero no en éste...» (128). Al referirse a los «repúblicos» que siguen las décadas de Tito Livio «por leyes y ordenanzas de buen gobierno» (108), quizá se inspira en el mismo pasaje de Livio que Maquiavelo comenta en un farnoso capítulo de los Discursos (I 58; «haec natura multitudinis est: aut humiliter servit aut superbe dominatur», Liv. XXIV 25,8), pero la temática no puede ser más distinta. En fin, también parece referirse en un lugar a la tesis maquiavélica de que las repúblicas deben tener «ricco il publico e gli loro citadini poveri» (Disc. I 37): «Dispuesta hay entre los que esto tratan cuál conviene más, que rey rico mande a súbditos pobres o rey pobre a vasallos ricos. Pero yo nunca tuve por buena ninguna de estas dos suertes.... (88). Todo ello mostraria las naturales limitaciones de comprensión de un texto tortuoso y pensado para una realidad muy particular como eran los Discursos de Maquiavelo, con to que resalta aún más la intencionalidad de la adaptación de uno sólo de sus capitulos.

Hispania, LVIL], núm. 195 (1997) 63-92 
fusión de maquiavelismo y bodinismo, y aplicando todo ello a las concretas circunstancias españolas.

Su punto de partida lo constituye la concepción bodiniana del ciclo de "nacimiento, crecimiento, estabilidad (o «estado florido"), declinación y caída" de los Estados, evocada con anterioridad. En efecto, el objetivo de la reforma será volver, a partir del estado actual de decadencia, al anterior "estado florido", como quería Bodin, o bien, siguiendo a Maquiavelo, en "reducir el ser del reino a sus principios" ${ }^{28}$. Recoge el argumento de Maquiavelo de que los principios de los Estados poseen cierta "bondad y reputación" en que se encierra el secreto de su expansion posterior ${ }^{29}$, pero, prescindiendo de la sutil doctrina maquiavélica de la dinámica del Estado, equipara los "principios" con el hecho material del "nacimiento" del Estado y con el concepto bodiniano de sestado florido", del que incluye la oportuna definición (94 s.). Tras confundir de este modo los orígenes con el apogeo del Estado puede situar los "principios" o "estado floridon de la monarquía española en el reinado de los Reyes Católicos. En efecto, después de las múltiples alteraciones que la habían dominado, fue en el reinado de Fernando e Isabel, y concretamente en el momento de la conquista de Granada, cuando "nuestra España en todas las cosas tuvo más alto grado de perfección, su crecimiento, aumento y estado floridon, de modo que «desde entonces se le pueden dar sus principios y nuevo nacimiento en perfección, bondad y perfecto estado de su monarquía real» ${ }^{30}$. Este apogeo residiría en las virtudes de la pareja real, pero sobre todo en la "justicia armónica» que imperaría, en lo que este reinado superaría a los posteriores, pese a la diferencia de riqueza y poder ${ }^{31}$.

28 «Y ansi toda la fuerza de los arbitrios estará en reducir el ser del reino a sus principios, que cuanto más a esto se acercare, más fuerzas y más salud cobrará; haciendo lo mismo en el desempeño de el rey, a forma que conservando el bien común vuelva a los mismos principios, que cuanto también a esto se allegaren las cosas del rey y del reino, más fuertes y firmes quedarán y en mayor bondad y fortalezas (93).

29 Apénd. 1 (\$ 1). En este Apénd. reproduzco los pasajes tomados literalmente del cap. de los Discursos, confrontándolos con el original.

30 «Y aunque la nuestra [república] ha tenido diversas alteraciones que la han mudado, el estado más florido que jamás tuvo le podemos atribuir a la espulsión que los Reyes Católicos de los moros en estos reinos hicieron; y desde entonces... Estos santos reyes con sus leyes y ordenanzas dispusieron las cosas de la paz y de la guerra a un estado seguro para la conservación y augmento de su república» (93). «Nunca nuestra España en todas las cosas tuvo más alto grado de perfección... que en aquellos tiempos en que a sus Reyes Católicos les resplandecieron todos los ditados de honra y gloria que se deben a la verdadera remuneración de la virtud los cuales correspondiendo entonces a la multitud de sus notables hechos pusieron esta monarquía en la cumbre de su perfección. Y muchas cosas llegaron a florecer en tiempo de estos gloriosos reyes que levantaron a España en el más alto estado de felicidad y de grandeza que jamás hasta alli tuvo...) (95).

31 «No faltarían causas para decir que despúes de los Reyes Católicos estuvo el reino más rico y poderoso y más acrecentado de estados, pero esto no basta para ser reputada una república por más dichosa, aunque los principes que la gobieman sean más sabios, más prudentes y mas virtuosos que los que gozaron del florido estado, porque la virtud que en los súbditos suele faltar es causa de no admitir la medicina y acertada cura del buen principe; mayormente que la perfección de un reino no consiste en la grandeza de estados, sino en la consistente y armoniosa justicia de entre los ciudadanos" (96); $\mathrm{y}$ añade dos ejemplos históricos tomados de Bodin (cf. Apénd. II).

Hispanida, LVIl/1, núm, 195 (1997) 63-92 
A este momento de esplendor sigue la decadencia. Cellorigo la concibe corno un proceso de descomposición natural, según la fórmula maquiavélica del Estado como un cuerpo al que diariamente se le van agregando partículas que lo corrompen ${ }^{32}$. En España este declive se observa tan sólo "de algunos años a esta parte», especialmente tras la anexión de Portugal ${ }^{33}$, y se evidencia en la pérdida del respeto hacia las leyes entre el pueblo. Adopta la explicación maquiavélica de la maldad natural de los hombres, así como su solución de un restablecimiento de la disciplina social mediante la periódica aplicación del terror: la "renovación del Estado», como traduce ${ }^{34}$, Y a continuación ensaya una adaptación de esta teoría a las circunstancias de la monarquía española.

Maquiavelo distinguía dos vías para efectuar el «retorno a los principios» o la "renovación" del Estado: mediante la "virtud" o mediante un "orden" o institución ad hoc. En el primer caso consistiría en lo que denominaba «ejecuciones excesivas y notables" de héroes individuales, acciones extraordinarias que tendrían como efecto impresionar a la masa de la población y restablecer su respeto hacia la autoridad pública ${ }^{35}$; en el segundo caso, en la acción sistemática de determinadas instituciones, como la censura y el tribunado de la plebe en Roma, que lograrían el mismo efecto mediante castigos ejemplarizantes. En los Estados que no poseyeran la virtud política de la antigua Roma, como las monarquías europeas de la época, únicamente esta segunda vía tendría efecto, sólo que en una forma más ruda y mecánica ${ }^{36}$. Cellorigo, como es lógico, no podía plantearse una refundación integral del Estado a la manera de Maquiavelo. Su preocupación se reduce al mantenimiento de la autoridad pública: garantizar la "observancia» de las leyes, y ello con carácter universal, sin tolerar exenciones de ningún tipo. Más precisamente, parte de la problemática de la eficacia de la política de "reformación» practicada en las monarquías de la época, y especialmente en la España de Felipe II, o lo que también denomina "renovación de las leyes» ${ }^{37}$. Estas leyes de "reformación" tenían a juicio de Cellorigo un gran alcance, pues «tocan a

32 Apénd. I (\$ 2).

33 Parece una crítica implícita de la anexión: «la caida siempre se ha visto de mal en peor de algunos años a esta parte, aunque con alguna demostración más después de la gran pérdida del cristianísimo rey don Sebastián de Portugal, por las resultas que della han procedidon (97).

34 Apénd. I ( $\$ 3$ ). El pasaje original se refiere a un procedimiento que se observaba en Florencia durante el gobierno de los Médicis en el siglo XV, denominado ripigliare lo stato, que Cellorigo traduce como "renovar las cosas del estado» y más abajo como urecuperar el estado», aunque con distinta aplicación (cf. nota 40). Es curioso cómo de inmediato añade una regla bodiniana a la regla maquiavélica: «y no es tan mal medio que no es necesario proveer en él para retirar el estado hacia sus principios, teniéndose cuidado con acomodar las ordenanzas al natural de los súbditos.»

35 Dichas «ejecuciones» serían el tipo de sacrificios patrióticos (de entre los que Maquiavelo prefiere los más inhurnanos) que se encuentran en la Historia de Tito Livio.

36 Maquiavelo pone el ejemplo del Parlamento de Paŕs, capaz de mantener a raya a la nobleza e incluso al rey, mediante sentencias que son el equivalente de las "ejecuciones" de los héroes romanos.

37 Otros autores trataban el tema de la «renovación» de las leyes en relación con el derecho de soberanía, cf. Maravall, Teoría española del Estado en el siglo XVII, $213 \mathrm{~s}$. 
gobiemo y buena política del reinon, y comprendían no sólo las leyes suntuarias, sino también las que deberían fomentar el espíritu capitalista en la agricultura y el comercio. Su ineficacia en tiempo de Felipe II se debió a la pérdida del hábito de la obediencia entre los súbditos ${ }^{38}$. El «retorno a los principios" habrá de ser la solución para que esta "renovación de las leyes" sea efectiva. Pero Cellorigo no se limita a la vía institucional que Maquiavelo reservaba para los Estados monárquicos, sino que imagina una renovación "mediante la virtud" de la que debería ser agente la alta nobleza. Ésta ha convertido en signo de dístinción la desobediencia a la autoridad pública, y esta actitud se generaliza por la influencia social de esa clase. Desearía Cellorigo que los nobles fueran «los primeros que siguiesen la renovación de las leyes", y por ello apela a su responsabilidad política ${ }^{39}$. Deberán ante todo proceder a «recuperar sus estados», es decir asumir la administración directa de sus propiedades ${ }^{40}$. Deberán además tomar conciencia de la función que les corresponde en la vida política de la nación. Evoca en este sentido la idea bodiniana de la familia como imagen del Estado, reduciendo su aplicación a la familia "del más ilustre" (99 s.), y afirma que la obligación de los nobles es adignificar al pueblo». Con ello estarán procediendo como los héroes romanos citados por Maquiavelo, que con sus "virtuosos y loables ejemplos" inducian al conjunto de la población a imitarles y rectificar su forma de vida ${ }^{41}$. La conclusión que obtiene de todo ello es que «en todas las comunidades bien orde-

${ }^{38}$ «El rey don Felipe Segundo nuestro ser̃or, procuró restituir los estados, con la ordenación de sus justas leyes, al más seguro y dichoso estado que ser pudo, sin dejar cosa que no hiciese ni ley que no renovase. Pero estaban ya los nuestros tan hechos a romper con la fuerza de las leyes que aunque fue grande su poder, su prudencia, su rectitud y justicia, cual jamás en ningún Príncipe Cristiano la hubo, no se consiguió el sancto fin de su buen celo, y la ley que un día salía a muy pocos no se guardava» (97). El lamento por el fracaso de Felipe II va unido con una alta estimación de su figura; dice de él que fue «el mejor rey que la Cristiandad jamás tuvo» (115; cf. 12), y afirma que la posibilidad de una reforma bajo su reinado fue real: entonces «por claros y evidentes discursos se vio y entendió, habia ya llegado el tiempo dichoso de la restauración de estos reinos» (5), lo que le indujo a componer los Memoriales sobre los moriscos.

39 «En cuanto es la observancia de las leyes y de todas las constitucio nes reales, ninguno [sc. medio] parece mejor que los títulos más principales de esta república... tomen la mano en ser ellos los primeros en seguir las ordenaciones del reino, así en el exceso de los gastos como en procurar el bien de sus haciendas en todo buen trato» (98). «Y universalmente sería muy útil a esta república que todos los principales del reino fuesen los primeros que siguiesen la renovación de las leyes y las demás nuevas constituciones que se hicieran, ansi en gastos y trajes como en todo lo demás tocante a la política; porque se ha visto que, aunque las leyes que tratan de la decisión y determinación de las causas están en su observancia, por ser ejecutores de ellas los letrados, que unos contra otros (patronizando a sus partes) las alegan, las que tocan a gobierno y buena política del reino, que son más importantes y más en bien comán de todos, se olvidan, ansí porque la nobleza no las admite en acto práctico como porque en pasando de los primeros ímpetus luego se olvidan» (99).

40 Dados sus deberes militares, los nobles no deberán convertirse en labradores, «mas sin obligarse a esto, pueden muy bien recuperar sus estados y reducirlos ai buen uso y aprovechamientos; los nobles de inferior condición podrán practicar una economía esclavista o dedicarse al comercio (98).

41 Apénd. I (\$ 4). Añade tras este pasaje el ejemplo de las leyes no escritas de Licurgo, que toma a la letra de Bodin (100) (cf. Apénd. II).

Hispania, LVlH/1, núm. 195 (1997) 63-92 
nadas antes ha de comenzar la obediencia de sus constituciones por los que son obedecidos, que llegue a los que han de obedecer " ${ }^{42}$. Todo ello equivalía a un intento de "politizar" o dinamizar el sistema de deferencia propio de una sociedad estamental, intento que resulta claramente ajeno a la intención de los autores en que está inspirado.

A continuación plantea la otra posibilidad de renovación. Si ésta no puede efectuarse "por virtud", habrá de hacerse por el "temor de la pena», es decir mediante los tribunales de justicia. Reproduciendo un pasaje de Bodin, señala cómo la ley es un simple mandato del príncipe que para ser efectivo necesita del concurso de los magistrados (101). Estos son los «ejecutores» que garantizan en último término el alcance universal de las leyes, ignorando cualquier pretensión de exención. Pone entonces los ejemplos maquiavélicos del Parlamento de París y de los tribunos y censores romanos, que lograron mantener, mediante sus acciones ejemplarizantes, la fuerza de las leyes en todo el territorio en que actuaban ${ }^{43}$. Y añade de inmediato un ejemplo de su cosecha, el de la Inquisición española, cuyos autos de fe, por el rigor con que se ejecutaban y por su alcance universal, cumplían la misma función de renovación que aquellas otras instituciones ${ }^{44}$. Todas estas "reseñas y muestras de justicia» deberán repetirse periódicamente, de modo que los ciudadanos, movidos por el terror que tales acciones producen, se mantengan obedientes a las leyes y no ocurra que la corrupción se extienda tanto que toda reforma sea imposible 45 .

Un poco más adelante no puede evitar Cellorigo extremar de forma característica la anterior doctrina. Al tratar de las obligaciones de los vasallos hacia sus reyes según una sección de las Partidas de Alfonso X, cita entre ellas el temor, distinguiendo primero entre el temor propiamente dicho, que se deriva del amor, se considera una virtud y se observa que produce en los súbditos la conveniente "vergüenza, respeto y obedecimiento», y el «miedo servil". Pero luego, en vez de condenar este último tipo de miedo como propio de regímenes despóticos, considera que "no es menos necesario" que el anterior, puesto que logra la completa sumisión del súbdito ante la seguridad de que cualquier desviación será castigada con el máximo rigor, y así puede mantenerse el buen orden del Estado ${ }^{46}$. Así, después de haber desarrollado una de las teorías más

42 100. Más abajo vuelve a tratar de la función política de la nobleza, haciendo un significativo añadido a un pasaje de Bodin con el que evidencia el especial papel que reconocía a la alta nobleza en el mantenimiento del orden público (cf. Apénd. II, $182 \mathrm{ss.}$.).

43 Apénd. 1 (\$ 5 y 6$)$.

44 «Los autos de la fe y demonstración de la gran rectitud que nuestro tribunal sancto de la Inquisición sin aceptación alguna de personas usa, ha aprobado en esto tanto, que da ser y esencia a la debida autoridad del sancto Oficio y recta justicia que en él se administran (102). Cellorigo demuestra de este modo la raíz maquiavélica de la Inquisición, tan discutida en la época. Es algo que pudo observar desde su condición de abogado de la Inquisición de Valladolid.

45 Apénd. I ( $\$ 7)$.

46 «No es menos necesario el miedo servil en los vasallos, porque no sólo han de temer al rey como hijos a padre, sino también como somo siervos a señor; teniendo miedo que si no hacen lo que deben y son obligados, caerán en el rigor de su justicia; que aunque esto es en fuerza servil, es muy necesario en las repúblicas para la conservación de la paz y de la justicia que el Rey administra» (119) 
innovadoras de Maquiavelo, no duda Cellorigo en recurrir al principio teocrático que contenían las Partidas, jugando conscientemente con el concepto teologico de "temor servil" ${ }^{47}$. Todo se resuelve en una estrecha preocupación por la conservación de la autoridad del Estado, como muestra su unilateral encarecimiento de la "obediencia» como fundamento del orden político ${ }^{48}$.

\section{LA RESTAURACION DE LA MEDIANIA}

Toda esta teoría de una reforma politica del Estado responde a la preocupación de Cellorigo por la afirmación del principio de autoridad, y podría considerarse una muestra de cómo la idea bodiniana de soberanía podía enlazarse con una concepción maquiavélica del poder político, todo ello guiado por una comprensión tradicional del poder represivo del Estado. Pero independientemente desarrolla Cellorigo un ideal reformista de raíz distinta, el que ha encontrado en la República de Bodin, especialmente en el capítulo de ésta titulado: "Que los cambios de las repúblicas y de las leyes no se deben hacer de golpe» (IV 3). Pasa asf del «terrorismo" maquiavélico a la idea de una reforma prudente, que ha de hacerse "poco a poco", nunca «de golpen. Lo curioso es que conserve para este otro procedimiento el mismo término de "retorno a los principios».

El artifice de la reforma bodiniana es una figura peculiar, el "políticon o el "sabio político" ${ }^{49}$. Como tal se presenta Cellorigo desde el principio, en oposición a los falsos políticos, ignorantes de la ciencia política o inclinados a la

47 El texto de las Partidas que sigue es el siguiente: «E como quier que temor e miedo es naturalmente una cosa, empero segund razón, departimiento ha entre ellos, ca la temencia viene del amor, e el miedo nasce de espanto e de premia, e es como desamparamiento. E el temor que viene de amistad es tal como el que ha el fijo al padre... $\mathbf{E}$ de tal temor como éste nascen dos cosas, vergüença e obedescimiento...» (Aqui cita los lugares biblicos de rigor sobre el respeto a los poderes constituidos, y sigue:) «E el otro miedo que viene del espanto e de la premia es atal, como el que han los siervos a los señores... Onde segund estas dos razones, deve el pueblo temer al rey assi como fijos a padres... Otrosí le deven temer como vassallos a seftor, aviendo miedo de fazer tal yerro porque ayan a perder su amor e caer en pena, que es en manera como de servidumbre) (Part. Il, tit. 13, ley 15). Además Cellorigo fundamenta su apreciación del «temor servil» con una especial referencja ("et de his timoribus satis...») a S. Tomás, Sum. Theol. II-1I, q. 19, a. 6-9, y con una glosa del Decreto de Graciano que toma del comentario de Gregorio López a la misma ley: «Atque etiam timor servilis introducit charitatem, gloss. 2 in cap. miror de paeniten. dist. l» (ed. 1600, f. 40): dos lugares donde se trata de un concepto estrictamente teológico.

48 No hay que «dar puerta a la inobediencia, madre engendradora de todos los daños que pueden venir a los reinos. Porque lo que los ha de preservar de ellos es ser los vasallos en todas las cosas obedientes al rey y a sus mandamientos» (119).

49 Al identificarse con la figura del politique Cellorigo prescinde, como era natural, de la cuestión de la tolerancia religiosa, y se queda con su faceta de político reformador. La teoria reformista de Bodin era una continuación del tema tradicional de la mutatio legum, sólo que poniendo la conservación de la soberanía como objetivo principal, decantándose por una reforma građual según un modelo unatural», y desarrollando una técnica política específica que en algunos puntos se confunde con el maquiavelismo. No faltó en España quien advirtiera los riesgos de tal concepción de la acción politica: un religioso valenciano, Fr. Francisco Dávila, denunció la obra de Bodin no sólo por las

Hispania, LVII/1, núm. 195 (1997) 63-92 
tiranía ${ }^{50}$. Así, en varias ocasiones se refiere a la impopularidad que esa profesión acarrea ${ }^{51}$ y a la oposición radical en que se sitúa frente al vulgo ${ }^{52}$, y desarrolla el tema de la "constancia» del político frente a los inconvenientes que en su actuación necesariamente encontrará y frente a las variaciones de la fortuna ${ }^{53}$. El «sabio político» está dotado con la «prudencia y sabiduría» o con la "ciencia" necesarias para vencer esos obstáculos y dominar el curso del Estado (53 s.). Para formarse una idea de éste no necesitará de la astrología, sino que podrá limitarse, entre las causas divinas, "naturales» (astrológicas) y humanas, según la tipología de Bodin, a estas últimas (15 ss.) ${ }^{54}$. También podrá prescindir, dada la estabilidad constitucional de la monarquía espanola, de la teoría bodiniana de los "cambios de estado" y centrarse en la problemática de una "monarquía real» 55 .

numerosas insinuaciones de heterodoxia que fácilmente detectaría un teólogo, sino además porque Bodin «asienta su república sobre una perpetua mudanza de leyes con la cual no puede estar la firmeza de la ley natural y de gracia» (cit. por AviLÉs, M., «La censura inquisitorial de la República de Bodin», Hispania Sacra, 37, 1985, 678).

so «Porque lo que más destruye las repúblicas es dar los príncipes crédito a personas que, ignorando las leyes de la buena política, los engolfan en un laberinto de infinitos errores...» (103); en materia de impuestos «conviene... que en ellos den forma los que hubieren tratado y experimentado la política y supieren la razón de estado... no admitiendo en esto si no es a los más prudentes...) (140); critica el exceso de "peticiones, memoriales y arbitrios, que, sin haber pasado por el estudio de las leyes y sin entender la razón de estado, es imposible salir acertados» (162).

51 Cita a Pierre Grégoire al principio de su De republica (103, 174).

52 Su enemigo particular es la tendencia a la irresponsabilidad propia del carácter español. La «filosofia de los españoles» no está dominada por el esoterismo ni la supersticiosidad, sino por su costumbre de culpar a los gobernantes de todos los males y desentenderse de los problemas con la excusa de que no hay remedio para nada (52 ss.). Añade como ilustración un ejemplo histórico de inconstancia del pueblo tomado de Bodin y la glosa bodiniana del «sabio político» (33 s., cf. Apénd. II). Más tarde concreta su intención al denunciar los peligros del populismo en la política fiscal.

53137 s., el primero de los «presupuestos y reglas» para la acción reformista que ofrece; "no se han de loar o vituperar las cosas del fin y suceso de ellas, ni medir el valor de los que las determinan con el medio de la fortuna, pues les basta procurar con buenas y prudentes consideraciones sacar verdaderos y ciertos efectos de las causas precedentes, en todo to que a la prudencia de los hombres le es posible alcanzarn (138).

54 Tampoco le parece de utilidad la teoría numerológica de Bodin: «Juan Bodino, siguiendo al mismo Platón, en el más oscuro lugar que escribió dice que las repúblicas vienen a perderse cuando la armonia falta», y tras resumir su teoría comenta: «no parece en sus seis libros que quiere hacer cosa más cierta que darnos a entender esto» (14 s.). Vuelve sobre el tema un poco más abajo: «Y afirmar Juan Bodino, siendo habido de algunos por tan docto, la mutación de las repúblicas por los números cuadrados y sólidos de siete y nueve, es dar que decir de sus obrass, tras lo que añade algunas rectificaciones con las que refuta la teoría (18 s.). En toda la sección sobre astrologia (13-19) asume Cellorigo muchas opiniones de Bodin, introduciendo las oportunas salvedades de un ambiente contrarreformista y concluyendo con un rechazo más terminante que el de Bodin. En cambio, usa sin nigún reparo un término como ugran Dios de natura» $(17,191$ s., cf. Apénd. II) que en Bodin tenía evidentes connotaciones heterodoxas.

ss «Mucho han escrito Pedro Gregorio, Juan Bodino y otros muchos jurisconsultos en razón de prevenir la caida y mutaciones de las repúblicas, pero todo cuanto dicen va enderezado a reparar los daños que provienen, o por levantarse los vasallos contra su señor, o los pobres contra los ricos, o por dar las repúblicas en diversas mutaciones. Como es mudarse la monarquia real en señoril o tiránica, 
Expone entonces la peculiar «técnica de reformación», como podríamos llamarla, que encontró en Bodin. La misión del político es la de salvador de un Estado en crisis: lograr la "reformación" o "restauración» del Estado. Esta reforma debe hacerse siguiendo un plan premeditado y en una coyuntura adecuada ${ }^{56}$. La regla principal será hacer los cambios "poco a poco", sin violencias ni riesgos innecesarios, pero a la vez siguiendo un método firme y diríamos "racional». De ahí la comparación con el médico: debe poseer la tenacidad de éste y no desesperar nunca, y a la vez mostrar una conveniente cautela y no arriesgar más de lo debido (163 s.). Más precisamente, debe procurar por encima de todo la conservación de las «leyes del estado", es decir la soberanía (174 s.) ${ }^{57}$. En consecuencia, el político deberá evitar los experimentos de importaciones de leyes y seguir la regla fundamental de acomodar éstas al «natural» del Estado (141 s., 163, $174 \mathrm{~s}$.) y del pueblo (66) ${ }^{58}$. Tan sólo se permite observar Cellorigo por su cuenta que puede darse una situación en que lo realmente peligroso sea la excesiva cautela ${ }^{59}$.

El programa reformador que Cellorigo derivaba de estos principios era doble: «desempeño del rey" y "desempeño del reino». Ambas partes debían coordinarse, y el desdoblamiento era necesario precisamente para que la reforma no se emprendiera según el orden menos conveniente. El "desempeñon del rey debía preceder al del reino, de forma que, según el principio de la correspondencia entre ambos, el reino desempeñaría al rey ${ }^{60}$. Ello se efectuaría mediante una contribución extraordinaria que recaería sobre todo en

o el estado aristocrático en popular, o reducirse cualquiera de las tres suertes de repúblicas más principales, que son la monarquia, la aristocracia y la democracia, en diferentes formas, o mezclarse el estado de las unas con el de las otras, o por rebelión de los súbditos, o por opresión de los que no lo son, y por otras causas exteriores, que suelen deshacer los principados y dar al través con los reyes y príncipes. De ninguno de estos accidentes se puede temer nuestra república, según el estado presente, por estar segura dellos conforme a reglas de estado la monarquía real de nuestra Españan (161).

56 Recomienda ta puesta en marcha de la reforma empleando una imagen bodiniana: «estando tan en sazón las cosas para las asegurar con la paz y retirar las velas mientras pasa la borrasca y se refuerza el navío, que según reglas de estado es bien seguirla hasta cobrar más fuerzas» ( 57 ; cf. 114). O también: «Para acomodar las cosas del reino es primero necesario prepararle y medicinarle, hasta ponerle en una previa desposición en que se le asienten las comodidades grandes que el tiempo le ofrece para ser rico y poderoso y exceder a las otras monarquías» (93).

57 De ahí que el objetivo sea «la reformación de todo lo que es contrario a la perpetujidad del Estadon (57).

58 El «natural de los reinos» y el «natural de las repúblicas», que Cellorigo tal vez confunde, equivalen en Bodin por un lado al carácter nacional, la geografia etc. («naturel des citoyens... nature des lieux, des personnes et du temps...», tema que desarrolla en V 1), y, por el otro, al tipo de Estado o forma de gobjerno («nature de la republiquen, IV 3 ).

59 Véase el añadido que introduce en el pasaje de Bodin que va transcribiendo (Apénd. II, 174 s.). También recurre al argumento de la snecesidad» (148).

(10 Reduce también esta idea a una fótmula: «que un empeño desempeñe a otro» (103). Crítica la «voz del vulgo» que exige una remisión absoluta de los impuestos, especialmente al principio del reinado («una inadvertencia muy envejecida en el pueblo») ( $90 \mathrm{~s}$;; cf. 135).

Hispania, LVII/1, tuím. 195 (1997) 63-92 
la clase de los "ricos" ${ }^{61}$. Muestra en este punto Cellorigo la conciencia de que es necesario seguir un método "científico" ${ }^{62} \mathrm{y}$ aplica ampliamente las reglas que encontró en el capítulo sobre fiscalidad de la República de Bodin ${ }^{63}$.

Seguiría entonces el "desempeño» o "restauración" del reino. Se aparta aquí Cellorigo de su modelo y propone una reforma social global, a la que designa con el término de "retorno a los principios». Su objetivo será restablecer el equilibrio social que el Estado poseyó en sus "principios", y que estaba caracterizado por el predominio de la clase media o "medianía" ${ }^{64}$. Ello implica restablecer el equilibrio entre las clases sociales. Utiliza el modelo de la división de la sociedad en tres clases según su riqueza, que formarían así la base triangular del Estado ${ }^{65}$. Es función del príncipe mantener esta figura, y ocurre que en España ha sufrido grave alteración. La solución consistirá en hacer que "el mediano pueblo medre y vuelva más hacia sus principios» ${ }^{60}$. Introduce aquí un análisis sociológico para mostrar cómo la clase media ha ido menguando por el deseo de sus miembros de ascender de categoría, por las excesivas cargas que debe soportar y por la proliferación de juristas, recaudado res y usureros, cómo la clase pobre se ha poblado de hidalgos y cómo la clase de «ricos» y caballeros se ha ido haciendo cada vez más gravosa para la nación ${ }^{67}$. Es necesario que se restablezca la clase media, y que con ella se recupere la

61 Todo ello debe considerarse como una intervención en la polémica sobre la situación de la hacienda real acentuada al final del reinado Felipe Il y que condujo a diversos proyectos de reforma bajo Felipe III (v. el reciente balance de FERnÁndez Albaladejo, P., Fragmentos de monarquía, Madrid 1992, 257 ss.). Proponía una contribución extraordinaria de 20 millones de ducados (136, 176), un «desempeño radical» que plantearian otros autores, como Alvarez de Toledo en su Memorial de 1602 (v. Sureda, La hacienda castellana, 46 s., 99). En su Alegación en favor de los judeoconversos de 1619 Cellorigo lamentaba que no se hubiera seguido esta vía: no podía aprobar la solución de los «millones», que en muchos aspectos suponía una claudicación del poder real.

62 Son significativas las siguientes expresiones: «De cómo se puede reducir a método el desempeño real», «Para reducir tanta máquina y que este gran caos y confusión se pueda comprender debajo de reglas de buena política...» (153); «No se puede comprender tanta diversidad de cosas que se ofrecen y tocan a esta materia si no es reduciéndolas a una generalidad” (169).

63 Toda la sección sobre «los necesarios presupuestos y reglas» para emprender el «desempeñon de la hacienda real (137 ss.) está directamente inspirada en el correspondiente capítulo de la República de Bodin (cf. Apénd. II), y hasta por una vez Cellorigo cita a su fuente: «Y no convendrá poco que los impuestos y rentas reales que fueren necesarios acrecentar o imponer de nuevo, se regulen y saquen a la forma y modo de los seis que propone Juan Bodino en los seis libros que escribió de República» (139).

64 «vuelva la república a la mediania de que se trata y a sus principios y al ser que en su florido estado antes tenías (169).

65 «Requiere forma triangular la basa en que se sustentan las repúblicas, a la cual si faltá algún ángulo o esquina, o cae de su asiento o es fácil de derribar’ (160).

66166.

67 166-168. El modelo no es totalmente coherente. Identifica la clase alta o de los «ricos» con la nobleza, al menos en los «principios» del Estado: «donde si había ricos, lo eran de veras; porque sólo este nombre merecían los titulados y caballeros que en hacienda y en valor ilustraban los estados y grandezas del reino. Los cuales, juntamente con los hidalgos nobles y ricos que antiguamente habia, eran en número tan proporcionado a los demás, que contrapesando hacia si el número de los otros 
economía productiva. Sin embargo, no puede limitarse a la «burguesía» y propone también una "restauración" de la nobleza, que pasará por su implicación en la vida económica nacional, aunque respetando su situación privilegiada en atención a la función "policial» que cumple dentro del orden monárquico ${ }^{68}$.

El "retorno a los principios» tal como aquí lo concibe Cellorigo cumple con el requisito bodiniano de ser un medio suave y gradual ${ }^{69}$. Evoca también la problemática bodiniana de la reforma social: la idea de la desigualdad de riquezas como causa principal de las alteraciones políticas $(52,159)$ así como la recomendación de evitar las soluciones igualitarias violentas, totalmente inapropiadas para las monarquias feudales de la época (164 s.). Pero mientras para Bodin los "medianos" forman una vaga categoría que aparece únicamente dentro de la perspectiva de su peculiar razón de Estado ${ }^{70}$, Cellorigo considera sobre todo la función económica de la clase media y adopta una comprensión digamos aristotélica de la misión del legislador en relación con ella ${ }^{71}$. Más fundamentalmente, se observa cómo parte de una concepción del

hacian estar en fiel las otras dos partes, pobres y medianos, conservándose en medianía los dos lados de pobres y ricos, que es la que siempre los sustentas (166). No tiene en cuenta, pues, a la alta burguesia. Sugiere luego que los trasvases de una clase a otra llegan a producir una clase especial, «un cierto estado y género de gente de por sí que, sin ser de los ricos ni de los pobres ni medianos, han puesto la república en el desconcierto que la vemos». No parece además que identifique a los «medianosn con una clase económica diferenciada (la burguesía); se trata más bien de una crítica social general que reponde a un impulso moral: los medianos son simplemente las personas decentes.

68 También trata Cellorigo esta cuestión en términos bodinianos (Rep. V 2): considera las casas de la nobleza como el fundamento de las monarquías europeas (cf. Apénd. II, 170; cf. 180); rechaza el que la nobleza represente una amenaza para el poder real ya que debe considerarse más bien como una garantía frente a las insurrecciones populares («siendo ellos los que han de hacer andar a raya al pueblo...", 181); considera apropiada por excepción la remisión de las deudas de la nobleza (cf. Apénd. II, $183 \mathrm{~s}$ ).

69 «No conviene usar de remedios violentos para restaurar esta república; pues su mal... no es tan agudo que no dé espera a los remedios, ni tan crecido que de su salud falte esperanza. Y ansí todos los que fueren en reducirla poco a poco a sus principios serán los mejores y los más proporcionados al estado» (175). Anteriormente ha señalado la conveniencia de proceder con la "república» "reduciéndola poco a poco a sus principios, porque es malo correr de un extremo a otro y quitar a la república los fundamentos en que estriban (140).

70 Así ve Bodin la función de la «clase media»: «la multitud de los ciudadanos, cuanto es mayor, impide mejor las sediciones y bandos; porque hay muchos que son medianeros entre los pobres y los ricos, y entre los buenos y los ruines, y entre los sabios y los necios; pues es cosa tan peligrosa estar los súbditos divididos en dos parcialidades sin medianeros» (Rep. V 2, trad. Añastro) (un pasaje que también sirve para ilustrar la visión maquiavélica que Bođin tenía de la cuestión demográfi ca, que Cellorigo no podría captar). Lo mismo en el pasaje citado más arriba, nota 20.

71 Habrá que hacer que la república, «sacada de los dos extremos en que está puesta con la excesiva riqueza de unos y gran pobreza de otros, siga un medio virtuoso que la compase y asegure..." (135); "que antes se conserve un medio virtuoso que abrace a ambos extremos, de suerte que se sustente el reino en su armoniosa composición...p (164). - El tema de la clase media es frecuente en el pensamiento político español de la época. Mateo López Bravo, en su De rege et regendi ratione $(1616,1627)$, proponía también, con un curioso acento maquiavélico: «Débense... cautelosamente aumentar en toda la ciudad los ciudadanos medios», y añadía un conjunto de medidas especialmente dirigidas contra la nobleza en la misma línea de Cellorigo (trad. en MeCHoulan, H., Un socialista español del siglo XVI, Madrid 1977, cf. 167, 177 ss., 285 ss.).

Hispania, LVIl/1, núm. 195 (1997) 63-92 
orden social y económico como un "orden natural", concepción totalmente extraña al pensamiento de Bodin, y en correspondencia con una tendencia moralista más propiamente contrarreformista ${ }^{72}$. En ese contexto debe situarse su crítica de la ociosidad y la mentalidad antieconómica y de la caduca moral aristocrática que imperaba en el país, que culmina en las magníficas fórmulas de España como «una república de hombres encantados que viven fuera del orden natural», o de que «la riqueza ha andado y anda en el aire” ${ }^{73}$. En ellas se resume el sentimiento más genuino del autor castellano.

La apropiación que Cellorigo hace del pensamiento de Maquiavelo y de Bodin, más allá de permitirnos una más correcta valoración de este destacado "arbitrista", nos muestra cómo se vinculaba la recepción de la nueva doctrina de la razón de estado, con todas las sofisticaciones y audacias de sus representantes más eminentes, a vivencias personales e historicas muy concretas. En un nivel teórico, el Memorial puede considerarse como un intento de conjugar esta nueva doctrina con la concepción política tradicional. Así, la idea maquiavélica del restablecimiento del orden político mediante el terror se asocia con la idea bodiniana de la soberanía del Estado y con la comprensión tradicional de la función represiva de la ley (el "temor de la pena») y del carácter trascendente de la autoridad política. Del mismo modo, la idea de reforma de Cellorigo también se diversifica según sus fuentes. Toma de los autores heterodoxos el principio del activismo político: por un lado, el "retorno a los principios" de Maquiavelo, la regeneración del Estado lograda mediante las wejecuciones extraordinarias" de individuos o instituciones que reafirman la jerarquía politica; por otro lado, el conjunto de "reglas de Estado" de carácter «conservador" que ofrece Bodin. Pero al mismo tiempo ensancha el alcance de la intervención política hasta convertirla en una auténtica reforma social inspirada en la idea

72 De ahí su división de la sociedad en tres clases. Cellorigo rechaza la igualdad por estar en contradicción con el orden social natural: «Y aunque no sería bien decir que todos hayan de ser iguales, no sería fuera de razón que estos dos extremos se acompasasen, pues el quererse todos igualar es lo que los tiene más desconcertados y confundida la república de menores a medianos y de medianos a mayores, saliendo todos de su compás y orden que conforme a la calidad de sus haciendas, de sus oficios y estado de cada uno, debieran guardar. Después que los espantoles echaron de sí los moros de España... aunque no han dado en guerras civiles... han dado en una competencia y emulación de los unos para con los otros... quetiéndose igualar en todo a todos, pervirtiendo el orden natural» (51 s.). El pasaje parece inspirarse en el siguiente de Bodin, para quien la desigualdad, independientemente de la justicia del orden social, es conveniente para la estabilidad política: «porque es cosa clara que no hay mayor odio ní más capitales enemistades que entre los que son iguales, y la envidia entre ellos es el origen de las sediciones y guerras civiles. $Y$ al contrario el pobre, el pequer̃o y el débil se pliega y obedece de buena gana al grande, al rico y al poderoso por la ayuda y beneficio que dél esperan (Rep. V 2 al princ., trad. Atrastro).

7379 (cf. 173), 90. Son los pasajes resaltados por Pierre Vitar con su característica intuición. Las referencias a la «ordenación natural» o «divina» de la economia y la sociedad son numerosas: $49,73,78,173$. El curso de la economía debe ajustarse a «la política moral de las buenas costumbres» (13); la «verdadera riqueza» se logra mediante «la natural y artificial industria» $(12,50,69)$. Hasta promete tratar en otra obra específicamente de la "reformación de costumbres» («por requerir largo discurso nos es forzoso reservarlo a lo que en otro lugar podremos dar escriton, 159). 
aristotélica de la promoción de la clase media y en la creencia en un orden socioeconómico natural. De hecho puede afirmarse que esta creencia en un orden natural es la que más peso tiene en el conjunto del Memorial: por ella se explica el uso de los términos "reformación" y "restauración" y la imbricación entre reforma política, social y económica, y regeneración moral. La contradicción entre acción política y orden natural que subyace al pensamiento de las autoridades que ha elegido es ignorada por Cellorigo. No está éste, pues, en el camino del racionalismo político moderno. Pero, aunque sólo sea de forma intuitiva, ha advertido la aparición de muchos de sus elementos y ha querido contribuir a la introducción de dicha ciencia política moderna en España.

En relación con la situación española, hay que señalar como la contradicción principal del pensamiento de Cellorigo su comprensión de la posición de la nobleza, pues impugna su ética y muchos de sus privilegios y desearía asimilarla en una estructurạ de clases «burguesa" mediante su integración en la vida econórnica, pero al mismo tiempo reconoce su preeminencia política y social e incluso espera que protagonice la reforma que habrá de resultar en el restablecimiento de la disciplina social y moral en España. En cambio, el tema de la "correspondencia" entre rey y reino aparece como un elemento original de su pensamiento: gracias a él no sólo puede abogar por una reforma fiscal con características poco habituales, sino que también ensaya una fundamentación de las obligaciones de gobernantes y ciudadanos. Este principio de la ucorrespondencia” puede verse además como el límite máximo de la teoría política de Cellorigo: sólo en un cuadro organicista podía justificarse la obediencia política sin cuestionar la estructura de clases dada. Mediante ese principio se equiparaba a los ciudadanos frente al Estado y se aseguraba la preeminencia del criterio del bien común. Pero el ordenamiento según ese criterio era estrictamente descendente, estaba en dependencia del concepto de "necesidad", que introducía una nota de excepcionalidad, y no cuestionaba la legitimación tradicional del poder real. Pese a estas limitaciones, debe reconocerse en el Memorial de Cellorigo un intento de ver la monarquía española como una "república" con una dinámica política propia y de explorar todas las combinaciones que permitía.

\section{APENDICE I}

Ofrezco a continuación el paralelo de los pasajes que Cellorigo toma literalmente de los Discursos de Maquiavelo, III 1. Indico las subdivisiones del capitulo de los Discursos según la edición de M. Puppo (Opere politiche, Florencia, 1969).

1. «todos los principios de las repúblicas y de los reinos siempre tienen bondad y proporción en sus cosas, mediante la cual crecen y se aumentan» (93) "[aunque España bajo los Reyes Católicos] quedase fortalecida y reducida (si podemos decir) a su proprio nacimiento, en el

Hispania, LVlij/1, nưm. 195 (1997) 63-92
"Perché tutti e principii delle sẻtte e delle republiche e de' regni, conviene che abbiano in sé qualche bontà, mediante la quale ripiglino la prima riputazjone ed il primo augumento loron. (5) 
qual no hay república que no tenga la bondad que le hace tomar la primera reputación y principios de su duración..." (95) "[los lacedemonios] vinieron a decaer de tal suerte de su primera bondad y loable reputación..." (96)

2. "Y aunque las causas se dejan entender, sólo se puede decir que, así como dicen los médicos que en el cuerpo humano, a quien son comparadas las repúblicas, cada día se va agregando alguna cosa que tiene necesidad de cura [ladillo: Quotidie agregatur in corpore, quod indiget curatione], asi ha ido entrando en la nuestra la mala constitución de su mal por medio de los accidentes intrínsecos y de los de afuera, que le han ido dispo niendo al estado en que están (95)

3. «Por ser este mal tan ordinario en las repúblicas, decían algunos que era necesario tornar a renovar las cosas del estado de cinco en cinco años; porque de otra manera era dificultoso poderse mantener los reinos de suerte que no decli nen; y haciéndose esto, dice, se reforman las costumbres inclinadas contra la ordenación de las leyes, con el nuevo terror que toman de ver castigar a sus transgresores $<y$ a los que tienen por grandeza no las respectar ni obedecer y tenerse exemptos de ellas ; y dan por razón que en perdiendo los hombres la memoria del castigo toman atrevimiento de tentar cosas nuevas» (97)

4. «Los cuales serán de tanta reputación y de $\tan$ buen ejemplo, que los buenos los desearán imitar y los malos tendrán vergüenza de tener su vida contraria a las de ellos. Los que particularmente hicieron en Roma estos buenos efectos fueron Horacio Cocle[s], Scévola, Fabricio, los dos Decios, Racula, Atilio (sic) y otros muchos de los caballeros romanos, que con sus virtuosos y loables ejemplos hacían en Roma casi el mismo efecto que hazian las leyes». (100)

5. "Y ansí lo hace el Parlamento de París, el cual (puesto que el Reino de Francia es más sujeto a las leyes y orde-
«E perché nel processo del tempo quella bontà si corrompe, se non interviene cosa che la riduca al segno, ammazza di necessità quel corpo. E questi dottori di medicina dicono, parlando de' corpi degli uomini, quod quotidie aggregatur aliquid, quod quandoque indiget curatione. Questa riduzione verso il principio, parlando delle republiche, sj fa o per accidente estrinseco o per prudenza intrinseca...p (6-8)

"Dicevano a questo proposito quegli che hanno governato lo stato di Firenze dal 1434 infine al 1494, come egli era necessario ripigliare ogni cinque anni lo stato, altrimenti era difficile mantenerlo; e chiamavano ripigliare lo stato, mettere quel terrore e quella paura negli uomini che vi avevano messo nel pigliarlo, avendo in quel tempo battuti quelli che avevano, secondo quel modo del vivere, male operato. Ma come di quella battitura la memoria si spegne, gli uomini prendono ardire di tentare cose nuove e di dire male; e però è necessario provvedervi ritirando quello verso i suoi principiin. (22-23)

[Las «ejecuciones" protagonizadas por un hombre guiado únicamente por su virtud] "sono di tale riputa zione e di tanto esemplo, che gli uomini buoni disiderano imitarle, e gli cattivi si vergognano a tenere vita contraria a quelle. Quegli che in Roma particularmente faciono questi buoni effetti furono Orazio Cocle, Scevola, Fabrizio, i dua Deci, Regolo Attilio ed alcuni altri; $i$ quali con i loro esempli rari e virtuosi facevano in Roma quasi il medesimo effetto che si facessino le leggi e gli ordini». (24-25)

«E si vede quanto buono effetto fa questa parte nel regno di Francia; il quale regno vive sotto le leggi e sotto gli ordini 
nanzas de su rey que otro ninguno) las hace guardar en toda observancia, aunque sea al mayor príncipe, haciéndolas renovar y resplandecer entre los suyos todas las veces que se ofrece la ejecución de ellas en alguna persona ilustre del reino". (101)

6. «En Roma, lo que más fuerza hizo fue la ordenación de los tribunos de la plebe y de los censores, los cuales animosamente concurrían a ejecutar las leyes contra el poder de aquellos que no las guardaban, en cuya ejecución fue tan notable la muerte de los hijos de Bruto, la muerte de los diez ciudadanos, de Melio Frumentario, la de Manlio Capitolino, la temprana muerte del hijo de Manlio Torcuato y la ejecu ción de los Scipiones, que, como excesivas y notables, cada vez que se hicieron pusieron a los hombres en raya. Y cuando después comenzó Roma a que esto no se hiciese sino de tarde en tarde, se fue dando lugar y anchura a los ciudadanos a que menospreciasen las leyes y a que después, para hacérselas guardar, fuese con mayor peligro y alboroton. (101 s.)

7. < 4 ansí algunos de los que mejor han escripto en materia de estado tienen por tan buenas, por tan necesarias y precisas estas reseñas y muestras de justicia, que fundan en buena política convenir muy mucho a las repúblicas $>$ que semejantes ejecuciones, sucedien do los casos, no se olviden; y que las ordenanzas por lo menos de diez en diez años se renueven. Porque al cabo de este tiempo los hombres comienzan a variar de costumbres, y si no sucede o se hace alguna cosa por la cual se les traiga a la memoria la pena y se les represente en los ánimos el temor, se olvidan luego de todo; y cuando a largo tiempo se quieren ejecutar las leyes, concurren tantos delin cuentes que no pueden ser casti gados si no es con gran daño del común...." (102)

Hispania, LVI//, núm. 195 (1997) 63-92 più che alcuno altro regno. Delle quali leggi ed ordini ne sono mantenitori i parlamenti, e massime quel di Parigi; le quali sono da lui rinnovate qualunque volta ei fa una esecuzione contro ad un principe di quel regno, e che ei condanna il re nelle sue sentenzen. (30-31)

agli ordini che ritirarono la repu blica romana verso il suo principio furono i tribuni della pleble, i censori e tutte l'altre leggi che venivano contro all'ambizione ed alla insolenzia degli uomini. I quali ordini hanno bisogno di essere fatti vivi dalla virtù d'uno cittadi no, il quale animosamente concorra ad esequirli contro a la potenza di quegli che gli trapassano. Delle quali esecu. zioni, innanzi alla presa di Roma da' Franciosi, furono notabili la morte de'figliuoli di Bruto, la morte de' dieci cittadini, quella de Melio frumentario; dopo la presa di Roma, fu la morte de Manlio Capitolino, la morte del figliuolo di Manlio Torquato, la esecuzione di Papirio Cursore contro a Fabio suo Maestro décavalieri, l'accusa degli Scipioni. Le quali cose, perché erano eccessive e notabili, qualunque volta ne nasceva una, facevano gli uomini ritirare verso il segno; e quando le cominciarono ad essere più rare, cominciarono anche a dare più spazio agli uomini di corrompersi, e farsi con maggiore pericolo e più tumulto». (17-20)

"Perché dall'una all'altra di simili esecuzioni non vorrebbe passare, il più, dieci anni; perché passato questo tempo gli uomini cominciano a variare con i costumi e trapassare le leggi; e se non nasce cosa per la quale si riduca loro a memoria la pena e rinnuovisi negli animi loro la paura, concorrono tosto tanti delinquenti che non si possono più punire sanza pericolo." (21) 


\section{APENDICE II}

Ofrezco a continuación una transcripción de los pasajes que Cellorigo ha tomado literalmente de la República de Bodin; únicamente dejo de transcribir los que son notas eruditas. Los agrupo según los apartados del Memorial de Cellorigo, e indico primero el capitulo de la obra de Bodin, en negrilla la página de la ed. reciente del Memorial, y entre corchetes la página correspondiente de la trad. de G. de Añastro de la República de Bodin (según la reciente ed. de J. L. Bermejo, Madrid, CEC, 1992, 1181 pp. en 2 vols.). Señalo entre paréntesis triangulares $\langle>$ los anadidos o frases originales de Cellorigo, y en cursiva algunas discrepancias con el original o la presencia de lagunas en la adaptacion. La relación seguramente no es completa, pero debe servir para mostrar el alcance de la asimilación del tratado bodiniano por Cellorigo.

Dedicatoria: - Dedicat.: (5 s.) «<por más asegurado que vaya su gobierno [sc. el de los reyes], cosas tales puede haber que siéndoles ocultas y> amenazando peligrosa tormenta, el aviso de ellas les sea muy necesario para reparar por todos lados la nave de su república. A cuyo favor y ayuda, por lo mucho que tendrá que hacer el patrón y pilotos, es bien que los demás acudan, y que por la seguridad de su rey y por correr todos un mismo peligro, pongan la mano en restaurar aquella parte, que según su lugar y puerto a cada uno toca... <este Memorial> en el cual para evitar el común naufragio se consideran los peligrosos encuentros y ocultas rocas a que esta república va a dar...» [137].

PARTE I. «De las opiniones que hay...» - IV 1: (14) «[Las repúblicas] habiendo tomado su principio de buenos y estables fundamentos y habiéndose reparado $\mathrm{y}$ asegurado contra la fuerza exterior y contra las enfermedades interiores, <les sucede un accidente que, participando de lo de dentro y de lo de fuera, se deshacen interior y exteriormente. Otros dicen que> habiendo poco a poco crecido una república en poder hasta llegar a la cumbre de su perfección y grandeza, en que no puede permanecer, por ser la variedad de las cosas humanas tan incierta y mudable, que a las más altas repúblicas suele allanar, viene a dar al través con su monarquía y a perderse cuando piensa estar más segura. <Otros lo atribuyen al hecho proprio de la naturaleza humana, teniendo por cierto que> las repúblicas y reinos envejecen a la larga, y que de sus enfermedades interiores vienen a tomar fin" [635]. IV 2: (14) ejemplo literal de Platón [672].

"Que es vano y supersticioso..." - IV 2: (15) «No sería justo no confesar los maravillosos efectos de los cuerpos celestes en todas las cosas naturales que asisten en la tierra y en el aire, en lo cual el inmenso poder de Dios se muestra admirable, dejándoles hacer las operaciones naturales que les dio desde el principio de su creación, sin que por ello se disminuya la grandeza y magnificencia del Criador, porque antes se declara y descubre más en hacer cosas tan grandiosas por medio de sus criaturas* [671]; (16 s.) «...esto no puede ser en las repúblicas, que no tienen su origen, su nacimiento tan unido y dispuesto en igual proporción a las influencias [celestes], como lo es el individuo del cuerpo humano, de que es muy diferente en nacimiento, crecimiento, <humores y disposición el mixto de> la república. Y cuando se diera caso por do constara las repúblicas estar sujetas y tener su dependencia después de Dios, de los cuerpos que del cielo influyen por esta ciencia, sería tan dificultoso de acertar cuanto se ve por los errores y contrariedades de los que hacel los efemerides... [672] < Hanse desvelado los profesores de esta ciencia en querer sacar de madre los secretos de 
natura, confundiéndose con> la impiedad de aquellos que quisieron hacer al mundo eterno y al criador ocioso, y nunca pueden asegurar cosa...” [682], ejemplos literales de conjunciones "grande, mediana, más grande y grandísima", aunque cualquiera de ellas «<importa poco $>$ [682]; (17) $«<Y$ aunque más digan, que> es común acuerdo de teólogos y filósofos que las cosas de este mundo no caminan por caso fortuito... <se han de reducir sus reglas a un fundamento católico, que es decir que> las causas de la mutación, declinación o caida de las repúblicas, o son naturales, humanas o divinas... [las causas naturales] <queda respondido no ser reales ni ciertas, porque> sus efectos se han de referir al sumo y omnipotente Dios de natura, sin atribuir a las criaturas lo que es del Criador. [681] Si son humanas o vienen por por medio ordinario y natural, que es una sucesión de causas encadenadas, dependientes unas de otras, así como Dios lo ha ordenado; o vienen por la voluntad de los hombres, que los teólogos confiesan ser libre por lo menos en las acciones civiles, porque no sería voluntad si fuese forzada, y ésta es tan mudable y tan incierta que sería imposible sacar de ella juicios seguros para saber en lo por venir las cosas que de ella dependen. Y si son divinas, que vienen por solo consejo y juicio de Dios, éste es tan inescrutable y incomprensible, que nadie le puede saber si no es cuando es servido de declarar su voluntad por revelación o inspiración divina, como ha hecho a los profetas mostrándo les muchos siglos antes el fin de los imperios y monarquías, verificado después sin faltar cosa en la posteridad» [671], (18) ejemplos literales de "Cipriano Levicio, Abufar y Abraham judío astrólogo" [681].

"Del error grande que los inferiores siguen..." - III 4: (32) «el príncipe tiene a todos debajo de su imperio y los magistrados (el particular), por más supremos que sean, no tienen súbditos ni autoridad pública de mandar como la tiene el rey... [543] los jueces inferiores... los cuales (el magistrado), estando como están debajo de la autoridad de los superiores, deben obedecer a su príncipe $<$ por ellos, $>$ y honrar a sus iguales, mandar a los de su jurisdicción, defender sus provincias buenamente, hacer rostro a las dificultades y justicia a todos», tópico literal de que el magistrado descubre al hombre [543].

"De cómo la república..." - V 2: (51) "<después de ser muy asentado en la materia de estado, ques no hay cosa más perniciosa que la excesiva riqueza de unos y la extrema pobreza de otros» [833]. VI 4: (52) $\ll<\ldots$ pervirtiendo el orden natural. Por el cual es muy cierto y sin duda que> unos nacieron para servir y obedecer y otros para mandar y gobernar, [1062] <como Aristóteles en sus Políticas y los que le siguieron lo sustentan...>»

"De las causas que algunos de los nuestros..." - IV 3: (53 s.) ejemplo literal de Roma y la batalla de Cannas [700] «en tal ocasión cuadra bien la prudencia del sabio ciudadano (el sabio político), que, viendo su república trabajada de todas partes, si halla que su rey es sabio y prudente, <como lo es,> y sus consejeros siguen y guardan las leyes de buen gobierno, <como se ve,> entonces hace ánimo y se promete buen suceso; cuando el ignorante pueblo, no considerando esto, pierde la paciencia y se entrega a la desesperación. [700] ...no haciendo [las influencias celestes], como no hacen, demostración cierta y segura, cuando fuera conocida la ciencia y la experiencia manifiesta, han de entender que no por eso quita que con la sabiduría y prudencia que Dios ha dado a los hombres se dejen mantener las repúblicas bien ordenadas en sus estados, y que hay ciencia en la política para prevenir las caídas dellas, particularmente por no estar, como no están, los sabios sujetos a la dominación de las estrellas (...) Porque si se ha descubierto que la fuerza de los astros, tenida de algunos por inevitable, se puede desviar, y que los sabios médicos han hallado medios para mudar las enfermedades y alterar las fiebres contra su curso natural y la sanan con facilidad, qué razón hay para entender que <un gobierno tan prudente y tan sabio como nuestro príncipe sustenta,>

Hixpania, LVII/1, num. 195 (1997) 63-92 
previniendo a las cosas del estado, no reparará con consejo y con remedios la ruina y caída de los suyos; mayormente que, si la fuerza del mal es tan crecida que sea necesario algún tanto obedecerle, deben fiar de tan buenos y entendidos médicos <como los que en el consejo de su príncipe asisten,> que con prudencia tomará los síntomas del día crítico y hará seguro juicio en el suceso de sus consejos" [699].

PARTE II. "De lo mucho que importa para fertilizar... - I 3: (59) ejemplos de severidad contra las mujeres entre romanos, hebreos (añade Cellorigo que las quemaban), alemanes, egipcios [170 s.]. III 5: (61) «Porque aunque la crueldad es reprensible, detiene los súbditos en la observancia de las leyes, y la demasiada blandura se las hace tener en poco, [580] <y> es grande engaño el que procede de parecerles a algunos jueces que la equidad consiste en remitir la injuria hecha a otro que con elia queda agraviado, siendo esto la mayor iniquidad que puede haber. Porque la equidad es de tal natural, que no tiene cosa común con el rigor ni con la misericordia, antes se parece a la regla lesbiana, <según dice un doctor, > que como es de plomo se dobla tan bien a una parte como a otra" [579]. I 3: (63 s.) "así como no hay cosa mayor ni más necesaria, según Euripides, para la conservación de las repúblicas, que la obediencia de la mujer al marido, así no debe el marido con título de serlo tratar mal a la mujer. [173] $<\mathrm{Y}$ si> la ley de Dios escrita, que dejó nombradas todas las cosas según la verdadera y natural propiedad de ellas, llamó al marido Bahal, que quiere decir señor y dueño, para mostrar que a él toca el mandar, y si las leyes civiles, para abajar la animosidad de las mujeres, y para dar a entender a los hombres cuánto deben excederlas en prudencia, valor y virtud, quieren que la honra y resplandor de la mujer dependa del marido, de manera que si él es noble, ella también lo sea, y si, por el contrario, es plebeyo, su mujer pierda la nobleza para que no le exceda en cosa, [173 s.] <también> es justo que <el marido > sepa mandar primero a sí mismo, dando a la razón el imperio. quitando a los apetitos la obediencia. $<$ Y siguiéndole la mujer, $>$ tendrá cada uno lo que le pertenece y guardará su puesto, que es la primera y más esclarecida justicia» [167].

"Que es necesario el uso de los esclavos..." - V 1: (66) “Y por esto es necesario acomodar la forma de las cosas públicas al natural de los reinos y las ordenanzas humanas a las leyes naturales. Muchos que no han considerado esto han enturbiado con injustas ordenaciones grandes y floridos estados, y hécholes caer en grandes inconvenientes» [795]. III 7: (68) «<En la justa monarquía de nuestro príncipe, que es de legítimo y natural señor,> no hay fundamento ni fuerzas más aseguras que <las riquezas> del pueblo, de las comunidades y concejos, <que con la mucha gente se adquieren>» y sigue como más abajo, 107 [628].

"Que el mucho dinero no sustenta..." - VI 2: (71) ejemplos literales de Paulo Emilio, Julio César, Perú [1007].

"Que conviene atraer a los súbditos al trabajo..." - I 5: (76) "no es habida por tan sabia y prudente la república que echa y expele de sí con justas leyes los ladrones, hombres y mujeres de mal vivir, cuanto la que les impide la entrada" [211].

"Del error que muchos siguen..." - V 4: (90 ss.) ejemplos de Tito, Vespasiano, Ciro, ael príncipe..., mirando a las leyes de la magnificencia, ha de mirar al tiempo, al lugar, al poder y al fin con que la hace... las leyes de la liberalidad, que mandan se mire bien a quién se da y lo que se da, en qué tiempo, en qué lugar y a qué fin y el poder de aquel que da, (...) lo cual si faltase no se podría decir largueza, sino prodigalidad, que de virtud pasaría a vicion [877].

"Lo mucho que importa para disponer bien el desempeño..." - IV 1: (94 s.) «aunque el estado florido no se entiende que es subir a la cumbre de perfección, porque no hay cosa perfecta en las cosas perecederas, y menos en las acciones humanas, entonces 
se puede decir estado florido de una república, cuando sube al más alto grado de su grandeza y hermosura, o, como otros dicen, cuando es menos imperfecto, que no se ve ni puede conocer hasta después en el tiempo de la declinación, como ahora se va reconociendo en la nuestran y ejemplo literal de Roma en tiempo de Papirio Cursor [640].

"La dificultad que hay de acertar..." - IV 1: (96 s.) ejemplos literales de Roma bajo Trajano y de Lacedemonia [641].

"Lo mucho que importa para que las leyes..." - I 2: (99 s.) «el justo gobierno en sus familias... <si> los jurisconsultos y los legisladores han reducido las leyes y ordenanzas de la política, de los colegios y de las familias, a una misma ciencia, entendiéndola económica por el justo gobierno que el sabio político (cabeza de familia) debe guardar entre los de su casa y de la autoridad que sobre ellos tiene y de la obediencia que le deben, <será muy grande argumento para que el pueblo reciba alegría con su gobierno el ver que en el de su casa los de quien es gobernado exceden a los demás.> Y aunque Aristóteles la tuvo por ciencia de adquirir bienes... así como la familia bien reglada es la verdadera imagen de la república (...) y así como el prudente gobierno de la casa <del más ilustre> es el verdadero modelo de el de un reino..." [157]. III 2: ejemplo literal de Licurgo y las urhetres» [510].

"Que en faltándose a las leyes..." - III 5: (101) «la fuerza de las leyes sólo está en mandar, prohibir, permitir y castigar, y la de los magistrados en lo ejecutar, a quienes es más propio la ejecución que a la propia ley, que es muda, y el magistrado la ley viva, que lo obra todo. (...) Y es que la ley no tiene otra cosa más que la prohibición (...) y el mandato del supremo príncipe, que, aunque imponga pena, nunca se sigue tras la inobediencia si no es declarada por los jueces que la hacen guardar. Por manera que toda la fuerza de las leyes estará, <o en el buen ejemplo de los nobles y más principales,> o en el ser de los magistrados, en quienes consiste la verdadera ejecución de los mandatos del supremo príncipe, que Demóstenes llama nervios de la república» [563].

"Cuán dañosa es a los reyes..." - I 8: (105) «siendo la justicia el fin principal de la operación del príncipe, y el príncipe imagen de Dios <y su temporal vicario en la tierra, $>$ todo lo que hiciere y determinare será a la medida y compás de lo que Dios ordena... [301]; (106 s.) <De que resulta la ignorancia de> los que quisieron decir que también tenía autoridad de tomar los bienes de otro... si el principe no tiene autoridad de trasumir los confines y términos de las leyes que Dios, cuya imagen es, ha puesto, tampoco podrá tomar los bienes de otro sin justa causa... [297] Y aunque no han faltado doctores que en cuanto a este artículo dan una limitacion, diciendo que, puesto que por derecho ordinario no le es permitido, lo puede hacer de poder absoluto... Porque lo que es poder absoluto sólo tiene título de aquellos en que se conserva el derecho de los más valientes (fuertes), donde la autoridad absoluta no es otra cosa que derogación de las leyes civiles y naturales contra la ley de Dios, que claramente dispone no ser lícito, no sólo tomar, pero ni aun desear los bienes de otro. Los que tales opiniones sustentan <no consideran que, aunque dicen que lo han estudiado y mirado, atropellan la conciencia, rompen con las leyes, pasan por la justicia y dan un salto sobre lo que manda Dios, y> son más peligrosos que los que lo ejecutan. Estos son los que provocan a los reyes a intentar lo que no les está bien, y a que con velo de justicia por cuenta del pueblo alimenten todas sus necesidades...» [296]. III 7: (107) «...reino, el cual no tiene fundamento más asegurado que los estados del pueblo, comunidades y concejos de su reino, que cuanto más ricos, más bien fortificados, más bien reparados, más fortifican la defensa y seguridad de sus príncipes y más los aseguran de los acometimientos dé sus enemigos. Demás de que, si es necesario (sacar dineros etc.) juntar las fuerzas y mantener la monarquía contra sus contrarios, resistir la tiranía de los tiranos, no se puede hacer si no es por los estados del pueblo de cada provincia,

Hispania, LVIU/, núm. 195 (1997) 63-92 
ciudad y comunidad del reino, el cual si queda muy enflaquecido y despechado, no le queda recurso alguno al rey a que acudir en la mayores necesidades». [628 s.]

"Lo que se ha de aconsejar al pueblo..." - II 5: (120 s.) "<Los príncipes y reyes comoquiera que sean han de ser> inviolables de sus súbditos y como sagrados y enviados de Dios» [440], ejemplo literal de Saúl y David [438 s.], "No hay cosa más replicada en toda la Escritura sagrada que la prohibición, no solamente de imaginar y tentar contra la honra del príncipe, sino también de los magistrados sus súbditos" [439].

"De lo mucho que importa la buena correspondencia..." - VI 4: (126) «siendo ley natural <que entre los hombres ha de haber mayores y menores grados y dignidades que los diferencien, $y>$ que unos nacieron para mandar y otros para obedecer" [1062]. II 3: (129 s.) "siguiendo el rey las leyes naturales, gobierna a sus súbditos suave y templadamente, y guía sus acciones por la natural justicia, que se deja conocer tan clara y resplandeciente como la luz del sol ...obedecieren ellos [sc. los súbditos] las leyes del rey y el rey las naturales. De lo cual, demás que quedará por ello la ley de la una y de la otra parte por señora y, como dice Píndaro, por reina obedecida y respetada, resultará una amistad, en recíproco amor del rey para con los súlditos y del pueblo para con su rey, $\langle y\rangle$ con muy dulce y alegre armonia.... [411 s.],

PARTE III. «De los necesarios presupuestos...» - I 8: (138 s.) «...la razón natural... conforme a ella, el bien público se ha de preferir al particular, y los súbditos no sólo deben socorrer su república con sus personas, pero, siendo necesario, por ella se han de desnudar de sus haciendas, [297] I 6 <corriendo la obligación recíproca que hay entre el> príncipe y los súbditos, de la una parte con obediencia, ayuda y socorro, los vasallos a su señor, y, de la otra, defensa, protección y amparo el rey a los vasallos" [236]. VI 2: (139) «al cual [sc. el medio de gravar a los súbditos] no se ha de llegar si no es cuando los otros medios faltaren, y en caso de muy urgente necesidad y aprieto grande de la república» [1001]; (140 s.) wes malo correr de un extremo a otro (...) y quitar a la república los fundamentos en que estriban, ejemplo de Nerón [1005 s.]. IV 3: (141 s.) «<Y así es ordenación y regla universal en todas las repúblicas (según los que de esta materia escriben), $>$ que para mantenerlas en su estado <o volverlas al que de antes tenían>, es necesario primero conocer el natural de cada una y las causas de su mal y daños que padece (...), y después seguir los remedios más conformes a su estado. Y si no está en mano de los que gobiernan mudarla, o si mudándola se ha de poner en riesgo de perderla, es mejor se asegure en su propio estado y se refuerce, de suerte que no perezca. Porque como a este propósito dicen los repúblicos, mejor cura es entretener al enfermo con convieniente dieta, que hacer prueba de sanar una incurable enfermedad con peligro de la vida" [701]. VI 2: (143) ejemplos de Severo y Enrique II [1034 s.].

"De cómo se puede reducir a método..." - I 7: (155) «<así pobres como ricos> tienen sus bienes, vidas y personas consagradas a su $<$ rey $>$ (señor), por ser ésta la verdadera señal de sujeción que el vasallo, y el vasallo del vasallo, deben al príncipe supremo... X aquella es la verdadera señal de sujeción que el vasallo (no en calidad de vasallos, sino como súbditos naturales) debe, cuando, corriendo la misma fortuna de su príncipe, <a quien le está bien proporcionar sus estados con semejante desigualdad, acude a ello con tanta voluntad,> que da muestras de la verdadera señal de su reconocimiento, estableciendo en sí de vivir y morir por él si necesario fuere” [247].

"De cuanta importancia sea al bien de los estados que su principe los visite..." IV 6: (157) «si las armas le asientan bien contra los enemigos, la justicia le viene bien en todos tiempos y en todos los lugares en favor de sus súbditos. [745] Y así como dijimos que los vasallos deben obediencia, ayuda, socorro y reconocimiento a 
su señor, así el príncipe debe justicia, defensa y protección a ellos; [743] <mayormente en> los negocios de estado, los cuales son tan propios del mismo príncipe, que, si los otros están a cargo de los magistrados, éstos están tan por cuenta suya que no los puede desamparar" [745].

"Si es bien que el príncipe se asiente a juzgar...» - IV 6: (158) «no dejan de hacer gran repugnancia las causas que para que los reyes no juzguen por sus personas todos dan [746] ...que la pena justa sea ejecutada en los malos y el premio se dé a los buenos. Y que esto lo haga y ejecute, reservando en sí la distribución de los premios, que son las dignidades, honores, oficios, perdones y mercedes, y todas las demás gracias y favores que conciernen a la magnanimidad y largueza del príncipe, remitiendo todo lo demás que tocare a las penas, condenaciones y confiscaciones, que son aborrecibles, a sus ministros y oficiales, para que hagan justicia y guarden sus leyes» [755].

"Del modo de restaurar al reino en particular". - V 2: (159) "lo que decía Platón que traía turbadas las repúblicas, era la pobreza y riqueza de los reinos, <así por los daños del un extremo como por los del otro>» [833].

"Del más verdadero y cierto discurso...» - IV 3: (163) «Porque habiendo tomado una buena ordenanza de otra república díferente de ésta, queriéndola acomodar al natural, a la disposición y estadio de la nuestra, no considerando la diversidad de la una a la otra, han estragado todo lo que pudiera ser en utilidad del bien público, por cuyo respecto se han perdido grandes y floridas repúblicas: [701] y ejemplo inmediato de prohibición de presentar memoriales en Atenas, Roma y Venecia [702].

«Del presto remedio con que es necesario acudir..." - IV 3: (163 s.) «si los sabios médicos $<$ (como dice un gran repúblico) $>$ han hallado medios para mudar las enfermedades y alterar las fiebres contra su curso natural y la sanan con facilidad, no será menos sino que también los que profesan servir a su rey, poniendo la consideración en las mutaciones o accidentes que suelen venir a las repúblicas y en el mal que padecen, repararán con consejo, con remedios y con lo demás que convenga, la ruina de la suya, y si la fuerza del mal hallaren tan crecida que sea necesario obedecerle, con todo eso, de los síntomas que habrán visto o verán en el día crítico, podrán sacar de dónde poder hacer seguro juicio del suceso que tendrá, y advertirá <cómo se han de reparar los crecimientos de la fiebre para que el mal no predomine>. (...) Y no sólo deben en esto imitar a los sabios médicos, sino a aquellos que con su mucha experiencia, cuando ven los mismos síntomas favorables, en lo más recio de la accesión tienen buena esperanza" [699]. V 2: (164 s.) «y a los más doctos les parece se buscase una igualdad, de muchos celebrada por madre de la paz y amistad de entre los súbditos, teniendo a la desigualdad por origen de todos los males, trabajos y calamidades que suelen venir por los reinos. (...) Y ha llegado a tanto la estimación desto, que muchos antiguos legisladores dividieron los bienes igualmente entre sus ciudadanos, a tanto que, a estos tiempos, Tomás Moro, canciller de Inglaterra, en su república dice que el único remedio para la salud pública es que los hombres vivan en comunidad de bienes..." y ejemplos literales de Licurgo, Solón y Agis [834], "<Todo lo que estos repúblicos procuraron introducir entre los suyos fuera bueno cuando se tratara de> formar de nuevo una repúbica, o se pretendiese renovar del todo un reino en tierras conquistadas, <donde el vencedor es señor de las vidas y de las haciendas y le es permitido disponer a su discreción de todo, [837] mas donde hay propiedad de bienes es revolver los humores y dar en mayores males. Porque,> quitando en un reino las convenciones legítimas, cancelando las obligaciones y anulando los contratos, quítase la fe a los comercios, dase lugar a haber poca fjdelidad, poca firmeza en las contrataciones, sin lo cual ni la justicia ni la humana compañía no pueden durar, que es por donde antes entra la perdición de los reinos. (...) Mayormente que si la

Hispania, LVIl/1, núm. 195 (1997) 63.92 
desigualdad tiene inconvenientes, bien examinado este negocio muchos mayores se hallarán en la igualdad y comunidad de los bienes» [835].

"Del reparo necesario a las muchas fundaciones...» -. V 2: (170) «.... cuya causa [sc. el poder de las casas nobles] todo el estado de la república se hizo más firme y estable. Porque es sin duda que la grandeza destos reinos, estando como está fundada sobre las grandes y ilustres casas como sobre grandes e inmudables pilares, si fuesen divididas perdería el apoyo en que se conserva la monarquía, que sustenta su gran peso en la consistencia de las casas ilustres y ricas (y sobre los cuerpos y colegios) <como los más firmes fundamentos que la casa real ha hecho producir de si misma $>$ [ [844].

"En qué forma se debe promediar el uso de los censos..." - IV 3: (174 s.) "solía decir Platón que no había cosa más dificultosa de proponer ni más dudosa de conseguir, que la introducción de nuevas ordenanzas, (...) las cuales si tocan al estado, con cualquier mudanza que por ellas se haga amenazan grandes peligros e inconvenientes. Porque mudar las costumbres y los estatutos que tocan a las sucesiones, a los contratos o a las servidumbres, de mal en bien, es en alguna manera tolerable, mas mudar las cosas que tocan al estado y lo que en él está introducido, es <revolver los hurnores y dar en otro más peligrosos. Y es que si a una envejecida república (aunque sea poco a poco) le remueven los fundamentos que la rigen y sustentan (y aunque sea por ponerle otros mejores), corre tanto peligro de caer, que a las veces es mejor dejarla pasar su curso que no apresurarse con mudanza de nuevas leyes... Mas esta máxima, aunque debe ser tenida en mucho, es en cuanto a decir que no conviene mudar cosa alguna de las leyes o costumbres de una república que mucho tiempo se haya conservado en buen estado, aunque se pretenda provecho aparente. [702] < Pero cuando la costumbre o la ley, por muy antigua que sea, la han puesto en estado que dél se ve y conoce, que el no mudarla es cosa peligrosa, en este caso no corre la razón de Platón ni de los que le siguieron. Porque sería querer quitar el remedio necesario a las cosas y la medicina a los enfermos y el reparo a todo lo que amenaza algún mal, y dar en otro extremo peor.> La regla más acomodada para promediar esto es que, conociendo -el natural de una república y las causas de la enfermedad y males que padece, se tomen los medios que basten para sustentar el estado en bondad y sanidad conforme a la disposición en que estuviere; de suerte que, si no se pudiere mudar, o que mudándola se ponga a peligro de perderla, se procure sustentar en su estado propio. Porque, <como tenemos otra vez dicho,> mejor es <(según reglas de buena política) > entretener al enfermo con diestra conveniencia, que hacer prueba de sanar una incurable enfermedad con peligro de la vida. No conviene usar de remedios violentos para restaurar una república, pues su mal, como hemos visto, no es tan agudo que no dé espera a los remedios, ni tan crecido que de su salud falte esperanzan [701].

"Del desempeño y restauración de las casas ilustres..." - V 2; (182 ss.) "A este modo dispuso su república Solón en cuatro órdenes, conforme a la hacienda y renta que tenían (...), y <aunque> Platón no puso más de tres en su segunda república, <con todo eso la dispuso a que de entre los ricos hubiese otros más ricos, para que los unos enfrenasen a los otros y los entretuviesen en sus pueblos, sin declinar a lo que suele alterar las monarquías $>$ [836], ejemplo de abolición de deudas en Roma [834].

«De lo mucho que importa para concluir el desempeño..." - V 2: (186) ejemplos literales de Aristóteles sobre Hipodamo y Platón y de T. Moro [836].

"Que en la distribución de los premios..." - V 4: (188 s.) "siendo el premio y la pena dos tan fuertes ataduras, bastantes para conservar la república en su buen estado* [872], «Y esto será fácil de conseguir con procurar conocer y tener noticias de las personas que por su virtud y valor merecen ser premiados, y que los que [no] tuvieran partes para lo que pretenden sean brevemente desengañados de los ministros... De 
esta manera <se desocupará la corte y> los importunos serán excluídos sin tener ocasión de ir descontentos del príncipe» [871]. IV 4: (189 s.) «<Será asimismo de mucho efecto para desterrar el pasado concurso de muchos cortesanos > poner a vista de todo el mundo los premios de la virtud, como blanco a que cada uno mire... $<\mathrm{X}$ haciendo... que> el primero y principal fin de toda su república sea la virtud, a que todo buen príncjpe y sabio legislador deben mirar.... [711]. V 4: (190 s.) «es muy ordinario que los que más merecen están más desviados de la esperanza y del afecto. Cuándo porque tienen por caso de menos valer y por deshonor el lisonjear y pedir como de limosna los premios que les son debidos, cuándo por la dificultad que sin tener favor en la empresa hallan y gastos que han de hacer, y las más veces sin esperanza, y otras porque, si sus honestas peticiones no son admitidas, no quieren algunos, si les toca el ser generosos, aguardar a la segunda despedida. [871 s.] Los ilustres y honrados caban [?] mucho en la vergonzosa denegación de lo que piden...". ejemplos literales de Calicrátidas y Lisandro [872] «Es de muy gran peligro en toda república repartir los honores y premios sin reparar en los méritos» [866], ejemplo literal de templo de la virtud en Roma [865] «Y así no hay que espantar si nunca hubo pueblo que tantos y tan valerosos hombres hubiese producido» [864]. VI 6: (191 ss.) «<Lo cual no menos se podrá esperar en toda bien ordenada república si el sabio rey que la gobierna,> según armoniosa proporción, regulando los premios por el peso y medida de la virtud, fuere dando las prelaturas a los más escogidos, la bolsa a los más leales, las armas a los más esforzados, y el trabajo a los más recios, (...) pues sería cosa impropia, <como dice un gran repúblico,> buscar un juez guerrero, un prelado animoso, un consejero valiente y un soldado escrupuloso. [1174] <Y puesto que es bien> mezclar los nobles y plebeyos, los ricos y los pobres, para dar recompensa a todos, ha de ser de suerte que los nobles sean reconocidos de los populares, con advertir que el caballero tan excelente en armas o en leyes como el plebeyo, es justo se le prefiera en los cargos de la guerra o en el de la judicatura, y que es bien que el rico igual en otra cosa al pobre, le preceda en los oficios que son de más honra que de provecho, y que el pobre se lleve los oficios más de provecho que de honra, con que todos deben estar contentos, pues al que es más rico no ha de procurar sino honra, y al pobre provecho. [1172 s.] ... así como por la desigualdad de los sones, aunque sean contrarios, se compone dulce y natural armonía, (...) así a los que gobiernan les es forzoso el compasar la incompatibilidad de los súbditos y las calidades diferentes en el armonioso gobierno de sus repúblicas. <Porque, según y comos aquel gran rey eterno, Dios único, puro, simple e indivisible, que levantado soble el mundo elemental celeste e inteligente, por voz y sones contrarios, hace dulce y natural armonía, y de las calidades diferentes de los elementos y de los movimientos contrarios, ligándolos con medios indivisibles, compone la armonía deste mundo y de sus partes, de la misma manera los gobernadores de la tierra han de ir dis* poniendo la armoniosa justicia distributiva y conmutativa, con ley justa y con equidad y paz, que es el fin de todas las leyes y juzgados y del verdadero gobierno, ...<por más que nuestra> república, <como todas las del mundo,> esté compuesta de buenos y malos, de ricos y de pobres, de sabios y de indiscretos, de fuertes y de flacos... [1177 s.] <nuestro esclarecido príncipe...> de tal manera se gobierna de la prudencia, de la fortaleza y de la templanza, tres virtudes morales acordadas juntas en la virtud contemplativa de su grande y raro entendimiento, que, [1175] concertando sus súbditos los unos con los otros y todos juntos en sí mismo..." [1174]. 